IZA DP No. 4476

Targeting Non-Cognitive Skills to Improve

Cognitive Outcomes:

Evidence from a Remedial Education Intervention

Helena Holmlund

Olmo Silva

October 2009 


\title{
Targeting Non-Cognitive Skills to Improve Cognitive Outcomes: Evidence from a Remedial Education Intervention
}

\author{
Helena Holmlund
}

London School of Economics

Olmo Silva

London School of Economics

and IZA

Discussion Paper No. 4476

October 2009

\author{
IZA \\ P.O. Box 7240 \\ 53072 Bonn \\ Germany \\ Phone: +49-228-3894-0 \\ Fax: +49-228-3894-180 \\ E-mail: iza@iza.org
}

\begin{abstract}
Any opinions expressed here are those of the author(s) and not those of IZA. Research published in this series may include views on policy, but the institute itself takes no institutional policy positions.

The Institute for the Study of Labor (IZA) in Bonn is a local and virtual international research center and a place of communication between science, politics and business. IZA is an independent nonprofit organization supported by Deutsche Post Foundation. The center is associated with the University of Bonn and offers a stimulating research environment through its international network, workshops and conferences, data service, project support, research visits and doctoral program. IZA engages in (i) original and internationally competitive research in all fields of labor economics, (ii) development of policy concepts, and (iii) dissemination of research results and concepts to the interested public.
\end{abstract}

IZA Discussion Papers often represent preliminary work and are circulated to encourage discussion. Citation of such a paper should account for its provisional character. A revised version may be available directly from the author. 


\title{
ABSTRACT
}

\section{Targeting Non-Cognitive Skills to Improve Cognitive Outcomes: Evidence from a Remedial Education Intervention*}

\begin{abstract}
A growing body of research highlights the importance of non-cognitive skills as determinants of young people's cognitive outcomes at school. However, little evidence exists about the effects of policies that specifically target students' non-cognitive skills as a way to improve educational achievements. In this paper, we shed light on this issue by studying a remedial education programme aimed at English secondary school pupils at risk of school exclusion and with worsening educational trajectories. The main peculiarity of this intervention is that it solely targets students' non-cognitive skills - such as self-confidence, locus of control, selfesteem and motivation - with the aim of improving pupils' records of attendance and end-ofcompulsory-education (age 16) cognitive outcomes. We evaluate the effect of the policy on test scores in standardized national exams at age-16 using both least squares and propensity-score matching methods. Additionally, we exploit repeated observations on pupils' test scores to control for unobservables that might affect students' outcomes and selection into the programme. We find little evidence that the programme significantly helped treated youths to improve their age-16 test outcomes. We also find little evidence of heterogeneous policy effects along a variety of dimensions.
\end{abstract}

JEL Classification: $\quad$ C20, I20, H75

Keywords: cognitive and non-cognitive skills; policy evaluation; secondary schooling

Corresponding author:

Olmo Silva

Department of Geography and Environment

London School of Economics

Houghton Street

WC2A 2AE, London

United Kingdom

E-mail: o.silva@Ise.ac.uk

\footnotetext{
This work is a substantially revised version of a paper previously circulated under the title "Unobservables and Matching as an Evaluation Method: Evidence from an Education Intervention". We would like to thank the statistical team of the Department for Children, Schools and Families (DCSF) and the staff at The Prince's Trust for help with the data, and Charlotte Fielder and Dylan Kneale at The Prince's Trust for helpful discussions about the delivery of the xl club programme. We would also like to thank Barbara Sianesi for help with her Stata $\odot$ routine psmatch2 and general discussions about matching methods. Finally, we have greatly benefited from comments by Sascha Becker, Simon Burgess, Rejeev Deheja, Steve Gibbons, Victor Lavy, Edwin Leuven, Fabrizia Melalli, Richard Murphy, Jeff Smith, Roope Usitalo and seminar participants at CEP-LSE, DIW-Berlin, HECER-Helsinki, PSI-London, RES Annual Conference 2009 and SOLE Annual Conference 2009. The views expressed in this paper are the authors' only and do not necessarily represent those of The Prince's Trust. We are responsible for any errors or omissions.
} 


\section{Introduction and context}

Governments around the world invest large amounts of resources into programmes aimed at improving the labour market prospects of young unemployed and raising the educational attainments of marginalized youths. In fact, training and educational expenditure absorbs a significant portion of public finances in developed nations (see OECD, 2005 and 2007). Despite these efforts, recent international evidence (OECD, 2005) suggests that a large number of students still 'fall behind' and leave school with little or no educational qualifications. In response to this problem, a growing number of remedial education programmes, targeting the most disadvantaged pupils at school, have been implemented and evaluated with encouraging findings. For example, Lavy and Schlosser (2005) provide evidence that a remedial education intervention focussed on increased instruction time for underperforming secondary school students in Israel was more cost-effective than alternatives based on financial incentives for pupils and teachers. Jacob and Lefgren (2004) show that summer classes offered to low achieving students (in $3^{\text {rd }}, 6^{\text {th }}$ and $8^{\text {th }}$ grade) significantly improved their reading and mathematics achievements for up to two years after the intervention. Further evidence is provided by Banerjee et al. (2007) who study two randomized experiments in India. Their two remedial education programmes, based on young female support-teachers and computer-assisted learning, substantially improved test scores of pupils in primary education. Finally, Machin et al. (2007) study an education intervention targeting poor learners in English inner-city secondary schools, named Excellence in Cities (EiC). The policy provided both learning support to 'difficult' students and more advanced teaching for the best 5-10 percent 'gifted and talented' students in under-performing schools. The results suggest that the EiC programme improved students' outcomes in Mathematics (though not in English), although the benefits were only evident for students with a sufficiently strong background, and not for the most 'hard to reach' pupils.

One distinguishing feature of these (and many other) remedial interventions is that they focus on improving students' cognitive outcomes by extending instruction time, coaching literacy and numeracy skills, tailoring teaching of the standard curriculum around students' specific needs and revisiting the 
material covered during the academic year in small classes. Stated differently, these programmes predominantly target cognitive skills with the aim of improving cognitive outcomes.

However, a growing body of research has shown that non-cognitive skills are similarly important in determining young peoples' cognitive educational achievements. Although non-cognitive skills are difficult to define (see ter Weel, 2008 for a discussion), these are usually conceptualized in terms of work and study habits - such as motivation and discipline - and behavioural attributes - such as self-esteem, locus of control and confidence. Recent evidence collected by Heckman and co-authors for the US (see, among others, Heckman and Rubinstein, 2001; Heckman et al., 2006; Cunha and Heckman, 2008) convincingly shows that young students' and workers' non-cognitive skills significantly affect their educational and labour market choices, as well as their school achievements and work success. Carneiro et al. (2007) provide similarly compelling evidence for the UK. Additionally, Knusden et al. (2006) and Cunha and Heckman (2008) show that non-cognitive skills are more malleable than cognitive abilities, and that the most 'sensitive' (productive) periods for investment in cognitive skills occur earlier in people's life (approximately during primary education) than 'sensitive' periods for non-cognitive skills, which concentrate during secondary schooling and the adolescent years. Carneiro and Heckman (2003) provide further evidence that non-cognitive skills are more amenable than cognitive abilities to being affected by policy interventions at later stages of one person's life. ${ }^{1}$

Despite these facts, surprisingly few policies have targeted directly and predominantly adolescent students' non-cognitive skills as a way to improve their educational attainments. Some exceptions are discussed in Heckman (2000) and include: the 'Big Brother/Big Sister (BB/BS)' programme; the 'Sponsor-A-Scholar (SAS)’ policy; and the 'Quantum Opportunity Programme (QOP)'. In fact, only the $\mathrm{BB} / \mathrm{BS}$ intervention focuses solely on 'mentoring' as a way to improve teenage students' motivation and awareness of education. However, the results of a randomized control trial evaluation of the policy show

\footnotetext{
${ }^{1}$ One exception is Segal (2008) who finds strong persistence in boys' misbehaviour at school (her proxy for non-cognitive skills) between $8^{\text {th }}$ and $10^{\text {th }}$ grade. However, in some parallel research, Segal (2009) confirms the importance of non-cognitive traits for young people's education and labour market outcomes.
} 
little evidence of a significant positive effect on pupils' GPA, even though treated students were less likely to skip school or use drugs and alcohol. On the other hand, the SAS initiative and QOP combined mentoring of students' non-cognitive/behavioural skills with some financial incentives/support and remedial learning activities. These interventions show significant effects on both young people's cognitive outcomes (e.g. GPA at $10^{\text {th }}$ and $11^{\text {th }}$ grade) and enrolment rates at college. All in all, it is fair to conclude that at present there is the little evidence about the effectiveness of policies that solely target adolescent students' non-cognitive skills as a way to improve their cognitive outcomes. ${ }^{2}$

In order to shed light on this issue, in this paper we evaluate a remedial education intervention called the $x l$ club programme that focussed on pupils aged 14 in England. The programme was administered in around 500 (out of about 2,500) English secondary schools, and on average one in ten pupils per year group in the targeted schools was selected for participation. Clubs operated on a closed two-year programme (between ages 14 and 16), with approximately 13 members who met for at least 3 hours per week guided by an xl club advisor (more details will be presented in Sections 2 and 3). Selection of students for the programme was based on teachers' assessment of one pupil's risk of educational exclusion (i.e. persistent truanting and school expulsion), and on perceptions of worsening educational performance and school disengagement. The most remarkable feature of the xl club programme was its explicit focus on improving students' confidence, self-esteem, motivation and locus-of-control - that is students' non-cognitive skills - as a way to improve school attendance and ultimately raise young people's end-of-compulsory-education (age 16) achievements. In our analysis we will concentrate on evaluating the effect of the policy on students' cognitive outcomes, that is on participants' test scores in standardized national exams at age 16 . This focus is partly dictated by the fact that, given that data at hand, the effect of the programme on test scores can be more properly assessed than on other outcomes (e.g. absences).

\footnotetext{
${ }^{2}$ One recent exception is the work by Pema and Mehay (2009) who study the impact of the Junior Reserve Officers' Training Corps (JROTC) on high school students' education and labour market outcomes. Even this programme, however, combines some 'standard' classroom teaching with more broad extracurricular activities.
} 
In fact, one crucial challenge in evaluating the policy is posed by the obvious non-random selection of students into xl clubs. Fortunately, the richness of our data, combined with access to repeated observations on students' test scores in standardized national exams at ages 11 and 14 (before entering the programme) and at age 16 (at the end of the programme), allows us to control for a variety of pupil observable characteristics and model unobservables that might affect both selection of pupils for the programme and their outcomes.

In terms of detail, we start our analysis by presenting least squares and propensity-score matching estimates that only exploit the cross-sectional nature of our data. ${ }^{3}$ These estimators simply compare age16 test scores of xl club students (treated) to attainments of similar (matched) pupils in schools where the programme was not being offered (controls). Note that we explicitly avoid looking for comparable nontreated students among the set of pupils enrolled in schools with an active $\mathrm{xl}$ club, but not taking part in the initiative (i.e. the non-treated in treated schools). This is because there might be spill-over effects of the $\mathrm{xl}$ intervention on non-participants, an issue to which we will return later in the paper.

We then go on to exploit the longitudinal dimension of our data and present estimates of the policy effect that combine least squares and propensity-score matching estimation methods with difference-indifferences and double-differences approaches to identification. Put simply, difference-in-differences estimates of the policy effects are obtained by comparing pupils' test scores immediately before (age 14) and right after (age 16) the policy, across treated and (matched) control students. This method allows to partial out time-fixed unobservables, such as ability or unobserved family background characteristics, that might simultaneously affect test scores and enrolment in an xl club. The double-differences approach instead exploits three points in time, and compares test score progression before the policy i.e. test score value-added between ages 11 and 14 - to progression after the policy - i.e. value-added between ages 14 and 16 - across treated and control students. These models (also called random-growth

\footnotetext{
${ }^{3}$ Rubin (1973) and Rosenbaum and Rubin (1983) pioneered matching methods to estimate policy-effects from nonexperimental data. However, it was mainly Dehejia and Wahaba (1999) and (2002) that popularized propensity-score matching in economics as a way to mitigate LaLonde's critique (LaLonde, 1986). Their original findings have been thoroughly scrutinized in Smith and Todd (2005) (see also a reply to their criticism in Dehejia, 2005).
} 
models; see Heckman and Hotz, 1989), further allow to partial out unosbervables that might determine enrolment in the programme and affect students' test score progress, such as increasing disengagement with the school activities and flagging motivation. Stated differently, double-differences models help controlling for linearly time-trending unobservable effects in students' outcomes. ${ }^{4}$

Turning to our results, cross-sectional estimates of the effect of the policy show a negative and significant impact on treated pupils' test scores at age 16 . However, our findings also provide suggestive evidence of negative selection into the programme based on pupil unobservables. This intuition is further backed by the institutional details on the delivery and workings of the xl club initiative. Consistently, difference-in-differences and double-differences estimates present a more encouraging picture with policy-effects close to zero or marginally positive. Using the method proposed in Altonji et al. (2005a) and (2005b) we provide an assessment of how important selection on unobservables should be, relative to selection on observables, in order to support the patterns displayed by our findings. Finally, we present some results that reveal little evidence of heterogeneous policy-effects along a variety of dimensions including pupil gender and eligibility for free school meals (a proxy for family income).

The remainder of this paper is organized as follows. Section 2 presents some institutional details about the English educational system and more information about the xl club intervention. Section 3 explains the data used in our evaluation, while Section 4 presents our main findings. Finally, Section 5 presents a concluding discussion. More details about our empirical models and estimation methods are provided in Appendix A and Appendix B.

\footnotetext{
${ }^{4}$ Meyer (2005) discusses the assumption underlying standard difference-in-differences methods, while Heckman et al. (1997) and (1998) set out the identifying assumptions of propensity-score matching differences-in-difference estimators and present related estimates of the impact of JTPA programme. More recently, Abadie (2003) has proposed a method to combine matching with difference-in-differences when only repeated cross-sections are available. Finally, Michalopoulos et al. (2005) used random-growth matching models to assess welfare-to-work programmes in a selection of US States.
} 


\section{Institutional and background information}

\subsection{The English education system and the $x l$ club intervention}

Compulsory education in England is organised into five stages referred to as Key Stages (KS). In the primary phase, pupils usually enter school at age 4-5 in the Foundation Stage and then move on to KS1, spanning ages 5-6 and 6-7. At age 7-8 pupils move to KS2, sometimes - but not usually - with a change of school. At the end of KS2, when pupils are 10-11, children leave the primary phase and go on to secondary school where they progress through KS3 to age 13-14, and then KS4, up to age 15-16, which marks the end of compulsory education. The last three years of secondary school, i.e. those spanning the end of KS3 through to KS4 (ages 13-14 to 15-16), will be the focus our analysis.

At the end of each Key Stage, pupils are assessed on the basis of standardized national exams (centrally set and marked). At KS1, pupils sit exams in English and Mathematics only, whereas at KS2 and KS3 students take tests in English, Mathematics and Science. Finally, at the end of KS4, pupils sit GCSEs (academic) and/or NVQ (vocational) tests in a range of subjects, although English, Mathematics and Science are compulsory for every student at this stage. Note that for each of the Key Stages the central government sets learning 'targets' (levels). Indicators of school total achievement are constructed from pupil individual test-outcomes on the basis of criteria devised by the Qualifications and Curriculum Authority; these are then published in publicly accessible school performance tables. For KS4, the individual-level target is to achieve at least 5 GCSE/NVQ at $A^{*}-\mathrm{C}$ level (on a scale of $A^{*}-\mathrm{G}$, with anything below $\mathrm{G}$ regarded as a fail), and schools are assessed on the fraction of students achieving this threshold every year.

Although age-16 achievements have substantially improved over the past decade thanks to substantial efforts by the UK government (McNally, 2007), the country is still cursed by a thick tail of young individuals who do not achieve the KS4 target and leave compulsory education without any 'good' qualification. Poor educational standards are particularly clustered in inner-city schools, with higher concentrations of students with family background disadvantages and learning difficulties. These 
schools have been targeted by a variety of government interventions, such as the Excellence in Cities program (Machin et al., 2007) and the Aimhigher initiative (Emmerson et al., 2006). The xl club programme under analysis here similarly targets schools with a high proportion of pupils from disadvantaged backgrounds and with poor educational records. However, rather than being a governmental intervention, the initiative was designed and administered by The Prince's Trust.

The Prince's Trust is the largest youth charity in the UK and is committed to improving the wellbeing of disadvantaged 14-30 year olds through increased opportunities and life skills, development of self-esteem, and by facilitating school-to-work transition. The xl club programme is one of The Trust's largest and most widely spread programmes, focusing on hard-to-reach students in secondary schools and tackling problems of school disengagement and exclusion. The Trust runs more than $1000 \mathrm{xl}$ clubs in around 500 secondary schools in England (out of around 2500). ${ }^{5}$ Broadly speaking, the programme targets 14-16 year olds at risk of truanting, exclusion and underachievement, and is run in clubs that use informal teamwork towards personal development and improvement in students' attendance patterns, motivation and non-cognitive skills. The clubs operate on a closed two-year programme with around 13 members who meet for at least 3 hours per week through the last two years of compulsory education, guided by an xl club advisor.

It should be pointed out that clubs are run in a reasonably independent fashion by participating schools. The main activities of The Trust involve: establishing minimum standards for running the programme; helping schools with the recruitment of an xl club advisor (often drawn from youth services or social services); providing learning materials for the programme; training of xl club advisors; holding of local network events for xl club advisors; monitoring quality and enforcing uniform standards of the programme across the national territory. However, the day-to-day management of the programme is

\footnotetext{
${ }^{5}$ The xl club initiative also has clubs running outside mainstream education, e.g. in pupil referral units or young offender institutions. Similarly, The Trust extended the programme to a small set of Scottish and Welsh schools. However, due to lack of data, we do not consider these here.
} 
down to the $\mathrm{xl}$ advisor, who is part of the teaching staff and thus responds to and coordinates with the school governing body, the school management team and the head-teacher.

Regarding the actual running of the clubs, these operate as an alternative to a GCSE/NVQ subject, although participants still have to take English, Mathematics and Science (regular students study on average ten different subjects). The main curriculum areas of the programme cover: personal, interpersonal and team skills development; citizenship and community awareness; community-based project management; entrepreneurial skills and enterprise projects development; preparation for the world of work and training. This curriculum was designed in order to target and improve some specific non-cognitive competencies, including: self-awareness, self-confidence, motivation, leadership, 'taking responsibility', citizenship, creativity, communication. Thus, in contrast with a wide array of remedial education interventions, the programme does not focus on providing support with standard areas of the learning curriculum, such as numeracy and literacy skills. In fact, the vast majority of xl club advisors does not come from a teaching background, rather from youth, social and careers services. This is because it is believed that these types of workers are in a better position at building relations with hardto-reach students, and working with them to improve their behavioural and non-cognitive skills. Once again, it should be noted that students selected for participation into an xl club are those with a history of truancy, school expulsion and misbehaviour, as well as general disadvantage, poor achievements and progressive disengagement from learning activities (more details will follow in the next section).

As for the work carried out by students in the areas of the xl club curriculum, this is not commonly converted into a GCSE/NVQ entry (thus contributing to the student's official records of educational achievement). Nevertheless, The Trust rewards students with an 'xl club Award' if they complete the necessary coursework. ${ }^{6}$ This requires students to regularly attend club activities, solve take-home

\footnotetext{
${ }^{6}$ This Award is recognized by ASDAN (Award Scheme Development and Accreditation Network). ASDAN offers a wide range of awards for young people of all abilities, with the aim to reward young people's skills as they complete 'personal challenges' in areas such as community involvement, work experience, citizenship and enterprise. Progressively, more ASDAN awards are being acknowledged and recognized by the Department for Children, Schools and Families and the Qualifications and Curriculum Authority.
} 
exercises and get involved in practical case-study solutions, as well as small business-operations development and events organization. Each students' course-work is documented in a series of folders (self-compiled, but monitored by xl club advisors), which are evaluated once per year during a centralized xl club 'assessment exercise'.

Note that, although achieving an $\mathrm{xl}$ club Award is seen as an important part of the programme, the main objectives of the $\mathrm{xl}$ initiative are to improve students' confidence and self-esteem; to enhance attendance and motivation; and ultimately to raise young people's end-of-compulsory-education achievement, including their KS4 (age-16) test scores. As already stated, in this analysis we will solely focus on test-based outcomes, as the effect of the policy on test scores can be more properly assessed given the data at hand. Holmlund and Silva (2008) present some evidence on the effects of the intervention on attendance records (available from the authors).

\subsection{School and student selection into the $x$ club programme}

Selection for participation into the $\mathrm{xl}$ programme follows a two-step approach. First, target schools are identified by The Prince's Trust staff on the basis of a (reasonably) well-defined set of criteria; second, within selected schools, pupils are chosen by their teachers and $\mathrm{xl}$ advisors on the basis of their personal assessment of pupils' needs. ${ }^{7}$ We discuss each step in turn.

Starting with schools, an initial selection round is carried out at a sub-national level by The Prince's Trust programme staff who manages the delivery of the programme in the various English regions. Within their region, local $\mathrm{xl}$ club staff invite applications from schools with a history of underachievement, poor attendance and high concentration of students with educational disadvantages or at risk of exclusion. Stated in other terms, priority is given to schools with persistently high concentrations of pupils eligible for free school meals (FSM, a proxy for poor family background) and with special education needs (SEN); to schools with a low fraction of students achieving the $5 \mathrm{~A}^{*}-\mathrm{C}$ GCSE/NVQ target discussed above; and to institutions with high rates of student absences. Information

\footnotetext{
${ }^{7}$ On average about 1 pupil in 10 per year group is selected for participation.
} 
on all these aspects is collected on a yearly basis by the Department for Children, Schools and Families (DCSF) for all schools in England for accountability and funding purposes, and can easily be accessed from publicly available performance tables and other data sources. Note that schools can also 'directly apply' to The Trust to be part of the xl club initiative (as opposed to 'be invited to apply'). However, given the popularity of programme, the charity has consistently received more requests than it can afford to support. This implies that not all 'bidding' schools are allowed in the programme and that some schools are de-selected from the network when their overall attainment improves above a certain level. Although this has caused some discomfort among schools excluded from the programme, it guarantees that the work of The Trust is prioritised in the most deprived schools (The Prince's Trust, 2006).

As for recruitment of students within schools selected for the programme, this takes place at the end of KS3 (age 14), when young underachievers at risk of exclusion, with low attendance records, lack of self-confidence and with broad behavioural issues are identified by their teachers and $\mathrm{xl}$ club advisors (not by The Trust's staff), and invited to join the club. Although the selection procedure is not fully codified, evidence in Browne and Evans (2007) and direct discussion with practitioners suggest that xl advisors and school teachers (who have known their pupils for up to three years) choose young students on the basis of their personal assessment of pupils' progressive disengagement with education; future risk of exclusion; and continuing deterioration of school performance and motivation. ${ }^{8}$ While potentially quantifiable and observed by the teaching staff, some of these characteristics are not observable to us. Thus, in our analysis particular attention will be devoted to understanding how different assumptions about the role of selection on unobservables affect our findings on the effects of the initiative.

Finally, there is some encouraging evidence about the 'enforcement' of participation in the clubs (see Browne and Evans, 2007). Most students willingly followed their teacher's advice to enrol, with only some 'forced' to take part in the activities. Put differently, the vast majority of students selected to

\footnotetext{
${ }^{8}$ Note that teachers and $\mathrm{xl}$ club advisors have little incentives to choose the 'most promising' students to take part in an $\mathrm{xl}$ club, i.e. pupils who might improve their performance even in the absence of the programme. Indeed, there is no clear-cut financial or reputational reward from having successful xl clubs. On the other hand, staff have incentives to select the 'hardto-teach' students, as this might improve their behaviour and make teaching regular students easier.
} 
participate in xl club activities did so, albeit with varying levels of enthusiasm. Also, about 95 percent of the selected students completed the two-year programme. Given this high compliance, our estimates of the policy-effects are closer to an average treatment-on-the-treated than to an intention-to-treat.

Before moving on, we emphasize that our empirical strategy will mimic the approach taken by The Prince's Trust in order to identify counterfactual students in comparable schools. In a nutshell, using aggregate school-level data on achievement, composition and rates of absences, we will first select a group of schools not running an xl club that is comparable to schools in the programme. Secondly, we will look for a set of comparable students in terms of their characteristics and prior achievements in comparable schools where an xl club was not present. In the next section, we explain this procedure in more detail alongside the data that we use.

\section{Data construction}

\subsection{Linking $x l$ club information to education administrative records}

The $\mathrm{xl}$ club programme was started in 1998 as a very small scale intervention among a restricted group of schools, but it has since then grown bigger and come to cover around 500 secondary schools in England (out of around 2500). In our analysis, we evaluate the effects of the intervention on the cohort of pupils aged 14 in 2004, who were selected to participate in that year and took their end of compulsory education exams at age 16, in the late spring of 2006.

Since 2001, The Trust has created electronic files containing the identity of all schools selected for the programme. Additionally, yearly files have been constructed by the charity that contain personal and background characteristics for all students enrolled in xl clubs. However, these files do not gather information on exams taken by the students at age 16, nor do they include data on previous test outcomes (KS2 and KS3) or official records on absences, eligibility for FSM and SEN status. Moreover, The Trust only collected information for pupils in the programme, while no data was assembled for pupils not taking part in the initiative to be used as a comparison group. 
In order to carry out our evaluation, we therefore need to make use of official records on pupil achievements and characteristics that are collected by the Department for Schools, Children and Families (DCSF) every year for each pupil in every school in the state-sector. ${ }^{9}$ The first source of information that we use is the National Pupil Database (NPD), which holds information on each pupils' assessment in the Key Stage tests throughout their school career. Since 2002, DCSF has also collected information on pupil's gender, age, ethnicity, language skills, any special educational needs or disabilities, entitlement to free school meals and other pieces of information via the Pupil Level Annual Schools Census (PLASC), which is now incorporated into the test score information in the NPD. The linked NPD-PLASC provides a large and detailed dataset on pupils' characteristics and their test histories, with details on students' achievement in the core subject areas - English, Mathematics and Science - at different stages. In our analysis, we make use of information on the cohort of pupils aged 14 and sitting their KS3 tests in 2004, matched to their KS4 exams taken in 2006 and KS2 achievement in 2001, and linked to their PLASC demographics in 2004. Various other data sources can be further merged in at school level - in particular each school's institutional type, composition, size and teacher numbers - which are available from the DCSF Edubase System and Annual School Census.

However, one crucial piece of information needed for our evaluation is not contained in NPDPLASC data, namely: an identifier for pupils starting an xl club in 2004. The only way of gauging this detail is by matching the official DCSF records with the data provided by The Trust on pupils taking part in the initiative. Unfortunately, the files collected by The Trust do not include the 'unique pupil identifier' commonly used by DCSF to match students across data sources and over the years, so xl club students cannot be directly linked to the educational census held by the Department. A mapping between the two sets of data was instead constructed with the help of the DCSF statistical unit using several fullydetailed individual characteristics, i.e. name, family name, date of birth, postcode of residence, gender, ethnicity and school attended. We next briefly describe the outcome of this linking procedure.

\footnotetext{
${ }^{9}$ As already mentioned, these data sets are collected by DCSF in order to construct school performance tables and determine school funding, predominantly based on pupil numbers and characteristics.
} 
The original number of students starting an xl club in secondary schools in 2004 for which we received data from The Trust was 5592. ${ }^{10}$ A mapping between The Trust's data and PLASC-NPD was constructed for 4128 students. This implies that we were able to link about 75 percent $(=4128 / 5592)$ of the students in the xl clubs files to the PLASC-NPD and to school-level information provided in the Annual School Census and Edubase. Of the 25 percent of students that we were not able to map, the largest portion was concentrated in a handful of underperforming schools that changed their status around year 2004 and 2005 (they became 'City Academies'). For these schools, consistent identifiers and information over time are hard to construct. Additionally, these schools underwent major restructuring of both facilities and teaching methods, and their student composition has been affected quite dramatically. For these reasons, we would have dropped these observations from our analysis in any circumstance.

However, several other observations were lost due to missing observations in some of the variables contained in PLASC-NPD, mainly KS2 and KS3 outcomes, so that the final number of treated students retained for the analysis dropped to 2233 (we further loose one participating school because of a 'common support' restriction; see next section). In order to shed light on this substantial sample-size drop, Appendix Table 1 investigates the characteristics of xl club pupils linked to NPD-PLASC, separately for students with and without any missing information, and for students that we were not able to link at all. The table shows that xl club students with missing NPD-PLASC data and xl club students not linked to administrative records are more often excluded from education, in care, ex/current offender and asylum seekers, than students for whom we have full information. This is reassuring, as most of these students will have spent/are spending some time out of education (offenders and excluded) or have recently entered the English school systems (asylum seekers), which helps explaining why we are not able to match pupils to the full set of official exam records and data. In Section 4.7, we briefly discuss the robustness of our results to the inclusion of observations with missing KS2 and KS3 test scores.

\footnotetext{
${ }^{10}$ Additionally, 306 students were in xl clubs in pupil referral units or young offender institutions. For these pupils, there exist no official educational records in PLASC-NPD. They are therefore excluded from our analysis.
} 


\subsection{Preliminary school-level selection}

As already mentioned, in order to identify counterfactual students and estimate the impact of the xl club programme, we start by extracting from our data a set of schools not running an xl club in 2004, but comparable to those in the programme. This mimics the approach taken by The Trust, where a first round of school selection was operated by the charity.

To this aim, the first restriction that we impose on our data is that we only consider Local Authorities (LAs, formerly Local Education Authorities) with at least one school with an xl club starting in 2004, which leaves us with 105 out of 150 LAs in England. ${ }^{11}$ The main reason for this exclusion is that, throughout our analysis, we include LA dummy indicators to control for LA-specific unobserved factors. LAs with no clubs would have thus dropped-out of our sample anyway. Secondly, schools with $\mathrm{xl}$ clubs in years prior to 2004, but not officially in 2004, are also dropped from the analysis, since these might still be running clubs or similar activities independently. This could add some confounding elements to our analysis and lead us to misestimate the policy-effect by comparing pupils in schools formally implementing the initiative to those in schools informally running xl-style clubs. Thirdly, schools starting an xl club in 2005 or 2006, but not in 2004, are dropped from the analysis in case there are spill-over effects from later clubs on previous cohorts. After excluding these observations, we are left with 351 schools with an xl club and 1780 potential comparison schools without a club in 2004 .

The characteristics (measured in 2003) of these xl club schools and non-xl club schools are presented in Table 1. The first two columns reveal that schools with an xl club have on average more students eligible for FSM than other schools (20 percent compared to 14 percent), a higher fraction of students with special education needs (SEN, 31 percent compared to 26 percent), and a lower proportion of students reaching the $5 \mathrm{~A}^{*}-\mathrm{C}$ GCSE/NVQ target (41 percent vs. 52 percent). Moreover, xl club schools were more predominately White (86 percent compared to 74 percent) and had higher absence rates (9.5 percent half-day sessions missed vs. 8.35 percent).

\footnotetext{
${ }^{11}$ Local Authorities are responsible for the strategic management of education services, including planning the supply of school places, intervening where a school is failing and allocating central funding to schools.
} 
In order to reduce some of these differences, we start by estimating the probability that each school is running an $\mathrm{xl}$ club in 2004 based on the following school-level characteristics: fraction of students with various ethnicities, shares of students eligible for FSM and with SEN status, share of students achieving 5 A*-C GCSE/NVQ, absence rates, school size, pupil-teacher ratio; and LA dummies. We model the probability of being an xl club school with a logit specification, and the associated marginal effects and standard errors are presented in Colum (3) of Table 1.

We then use the predicted probabilities of participation for $\mathrm{xl}$ club and non-xl schools from the logit model to select only schools that belong to the 'common support' area. Figure 1 displays plots of the probability distributions for the two groups, and the note to the graph provides exact details on the 'common support' region stretch. After this restriction, the number of non-xl schools shrinks to 1683 , whereas the number of $\mathrm{xl}$ club schools is basically unaffected (350 out of 351$)$. These 'common support' schools constitute the core sample of our analysis, which we will use to 'match' $\mathrm{xl}$ club participants to counterfactual students in schools not running the programme.

As already noted, in our evaluation we do not consider students in xl club schools, but not enrolled in the initiative, as potential control units (non-treated in treated schools). This is because there might be spill-over effects of the $\mathrm{xl}$ club intervention on non-participants. For example, xl club students might become less disruptive as a result of the policy, thus positively contributing to the learning of others during normal class-time (i.e. they became 'better' peers). Additionally, since xl students dropped one subject, spill-over effects could operate through smaller class size and through more teacher attention devoted to the learning of students remaining under the regular curriculum. All in all, we believe nontreated pupils in treated schools do not constitute a potentially useful comparison group. We will return to this issue in Section 4.7, where we present some additional findings and robustness checks. 


\section{Empirical findings}

\subsection{Descriptive statistics}

The descriptive statistics on the main variables used in our analysis are tabulated in Table 2. Columns (1) and (2) present information on xl club pupils and on students in schools where an xl club was not running, respectively. There are 2233 treated youths and 259,189 potential controls. Additionally, Columns (3) and (4) tabulate the difference between Columns (1) and (2) and the t-statistics on a test for the significance of this difference. Finally, while the top panel of the table presents measures of pupil attainments at various Key Stages, the bottom panel tabulates students' characteristics.

Attainments at KS2 (age 11) and KS3 (age 14) are presented as the average standardized test score (zero mean, unitary variance) across the three compulsory subjects, i.e. English, Mathematics and Science. The original variables used to obtain these indicators are pupil 'test scores', which vary between 1 and 100 for each of the three subjects and at each of the two Key Stages. As for KS4 (age 16) tests, we make use of pupil 'point scores' in English, Mathematics and Science (varying between 0 and 8); these are indicators of total achievement devised by the Qualifications and Curriculum Authority (QCA) and used by DCSF in the performance tables (see discussion above). Point scores are based on allocating points to different grades, and aggregating across types of qualifications using appropriate weights (details available from DCSF or QCA). To make age-16 scores comparable to earlier Key Stage grades and construct measures of educational value-added, we also average age-16 point scores across the three core subjects, and standardize the averaged measure to have zero mean and unitary standard deviation. In Section 4.7, we present some robustness checks where we use KS4 point scores averaged over a wider range of subjects. Finally, Table 2 also reports measures of value-added over KS2 to KS3 and KS3 to KS4, and a measure of the change in pupil value-added between KS2 to KS3 and KS3 to KS4. These are obtained by taking single and double differences in standardized test scores over adjacent Key Stages.

Some interesting findings emerge from the table. First of all, it is evident that $\mathrm{xl}$ club students perform significantly worse than students in non-xl club schools over the different Key Stages: their 
performance is between 1.2 and 1.4 standard deviations below that of non-xl club students. Note that we investigated whether these differences are particularly concentrated in one of the three core subjects, but we found that xl club students achieve similarly low grades in English, Mathematics and Science. As for the (KS3-KS2) and (KS4-KS3) value-added measures, these are centred around zero for students in non-xl club schools, but negative at both stages for $\mathrm{xl}$ club students and significantly lower than for regular students. Finally, the acceleration in pupil achievement over the three key stages, that is the double difference (KS4-KS3)-(KS3-KS2), is marginally positive for xl club students and marginally negative for pupils in non-treated schools, although the difference across the two groups is not significant. These patterns reflect a slowing down of the positive trend in non-xl club students' achievements, and a flattening out of the negative slope of xl club pupils' value-added between KS2 to KS3 and KS3 to KS4.

As for the individual characteristics, xl club pupils are more likely to be male and eligible for FSM, and to hold special education needs (SEN) with varying degrees of severity (the most severe being 'SEN, with statement'). Interestingly, they are also more likely to have English as a first language and to be Black, and less likely to be Asian and Chinese. These findings are not surprising, as Black English-born male students, with poor family background, are amongst the poorest achievers in England.

An array of additional school-level characteristics and information about the neighbourhood of residence of each pupil (obtained from the GB Census 2001) are also included in our analysis. These are presented in Appendix Table 2. One thing worth mentioning is that, thanks to our preliminary school selection (see Section 3.2), school characteristics look reasonably balanced across the two groups, especially relative to the imbalance in pupils' attributes. As for neighbourhood characteristics, $\mathrm{xl}$ club students tend to live in areas with higher concentrations of unemployment and social housing, and marginally lower levels of educational achievement of the adult population. 


\subsection{Propensity-score estimation results}

In this section, we present our findings about students' propensity-scores, i.e. estimates of the probability of being selected for participation in an xl club based on an set of individual, school and neighbourhood characteristics. These will be used in the next sections where we evaluate the effect of the intervention using propensity-score matching methods (more details provided in Appendix A). Empirically, we adopt a logit specification and fit the following model:

$$
\operatorname{Pr}\left(d_{i}=1 \mid Z\right)=\Lambda(Z \omega)
$$

where $d_{i}$ is a binary indicator taking value one if pupil $i$ is enrolled in an xl club and zero otherwise; $Z$ is a set of characteristics that vary depending on the exact specification of the empirical model; $\Lambda($.$) is$ the logistic cumulative distribution function; and finally $\omega$ is a vector of parameters.

Our results are reported in Table 3. All columns include a broad array of individual characteristics as well as school and neighbourhood controls and LA dummies (see notes to the table for details). However, Column (1) does not include any control for previous achievement, whereas Column (2) controls for attainments at KS3 and Column (3) includes test scores at KS2. Finally, in Column (4) we simultaneously include test scores at KS3 and value-added between KS2 and KS3 (KS3-KS2) to investigate whether both levels and trends in performance affect individuals' chances of taking part in an $\mathrm{xl}$ club. Note that throughout the table we report marginal effects and standard errors (in round parenthesis), as well as odds ratios (in italics, square brackets).

Column (1) confirms some of the intuitions gathered from the descriptive statistics presented above. Male pupils and students eligible for FSM or with SEN are significantly more likely to be enrolled in an xl club. Pupils with 'special education needs - action plan/plan plus'(a milder level of educational disabilities) are 7.6 times more likely to be selected into the programmes, although students with more severe learning disabilities ('SEN, with statements') are only 5.4 times more likely to participate in an xl club. This finding possibly reflects the fact that pupils with the latter characteristics are more likely to be 
involved in other more targeted activities, than pupils with milder forms of SEN. As for differences across ethnic groups, these are still evident but less pronounced than in the descriptive statistics.

More interestingly, as shown in Columns (2) and (3), average low achievements across English, Mathematics and Science at KS3 (age 14), right before the students were selected for the programme, and at KS2 (age 11), at the end of primary schooling, are strong predictors of the chances of enrolling in an xl club. For example, the odds ratios show that the probability of participating in an xl club decreases by approximately a factor of five when we increase pupil achievements at KS3 by one standard deviation; the corresponding factor for KS2 is approximately 2.5. Given that the differences between x1 club pupils and other students in terms of KS3 and KS2 test scores are in the order of 1.2/1.3 standard deviations, these effects are substantial. Finally, in Column (4), we include KS3 test scores and (KS3KS2) value-added simultaneously. The results show that, while the KS3 variable retains its size and significance, test score value-added between ages 11 and 14 is not a strong predictor of one pupil's chances of being enrolled in an xl club. Nevertheless, while not significant, the marginal effect and associated odds ratios still suggest that pupils with slower progression between KS2 and KS3 are marginally more likely to participate to an $\mathrm{xl}$ club. All in all, there is some weak evidence that both levels of achievement and progress between Key Stages help predicting enrolment into an xl club.

Next, Figure 2 presents histograms of the implied probability of treatment, i.e. propensity-scores, for participants and non-participants for the four different specifications of Table 3. Across all panels, the graphs do not present a particularly reassuring picture. In particular, the estimated common support for the distribution of $\operatorname{Pr}\left(d_{i}=1 \mid Z\right)$ for treated and untreated units seems quite limited. This result is surprising given that the set of conditioning variables $Z$ used in our specifications contains detailed information about pupil history of achievement and background. Nevertheless, similar patterns have been documented by previous research in the field, for example by Heckman, Ichimura and Todd (1997).

However, it has to be emphasized that the histograms in the figure hide a substantial part of the empirical action. In fact, it should be noted that the diagrams show fractions within the treated and control groups, and that the group of untreated pupils is about 100 times larger than the group of treated 
students. Therefore, although a predominant fraction of control units has near-zero probability of treatment, the raw numbers of individuals with high estimated propensity scores for the two groups are fairly comparable, in particular at the very top end. For example, 559 treated observations have an estimated $\operatorname{Pr}\left(d_{i}=1 \mid Z\right)$ of 21 percent or higher, compared to 760 untreated units. For even higher probabilities, we find that 110 treated and 24 untreated students have an estimated probability at or above 63 percent, and that 23 treated and 5 untreated pupils have probabilities of 80 percent or above. This implies that the common support area stretches over a much larger region than it would appear from the graphs and that, thanks in part to the large size of the potential control group, xl club pupils can be matched to counterfactual students over most of the $\operatorname{Pr}\left(d_{i}=1 \mid Z\right)$ distribution.

Nevertheless, another crucial fact emerges from these plots: the estimated propensity-scores for treated students are also clustered on low predicted probabilities. About 50 percent of the treated students (1165) have estimated probabilities of treatment of 0.06 or lower. Once more, this is similar to the findings in Heckman, Ichimura and Todd (1997). This evidence clearly suggests that factors that are unobservable to us - but not to the teachers and xl club advisors - must have played an important role in the assignment of pupils to the programme. Indeed, this is fully consistent with the discussion presented above about the factors that influenced staff choice of pupils for the xl clubs, which included potential risk of school exclusion, flagging motivation and progressive disengagement from school activities. In Section 4.4 , we will try to deal with the consequences of this issue in detail.

\subsection{Cross-sectional least squares and propensity-score matching estimates of the policy-effect}

We begin our discussion by presenting estimates of the average treatment-on-the-treated (ATT) obtained exploiting only the cross-sectional dimension of our data. Put simply, we estimate the effect of the policy by comparing age-16 test scores of $\mathrm{xl}$ club students (treated) to the attainments of similar (matched) pupils in schools where the programme was not being offered (controls). To do so, we use both ordinary least squares (OLS) and a propensity-score matching approach; more details are provided in Appendix A. The advantages and drawbacks of a matching approach relative to OLS have been extensively 
discussed in the literature (see Imbens, 2004; Dehejia and Wahba, 2002; and Smith and Todd, 2005), as well as the properties of different algorithms used to obtain matching estimators of the ATT (see Dehejia and Wahba, 1999; Frolich, 2004; Smith and Todd, 2005; and Caliendo and Kopeinig, 2008). However, broadly speaking, both cross-sectional least squares and matching estimators rely on the same assumptions in order to yield consistent estimates of the effect of the policy, namely that conditional on (large set of) observable characteristics, treatment assignment is as good as random. Stated differently, the assumption is that selection operates only via observables, and that unobservables are unrelated to the probability of treatment and outcomes in the absence of treatment, conditional on observables. In the matching literature, this is often refereed to as Conditional Independence Assumption (CIA).

In Table 4, we present findings obtained using four different specifications of the set of controls included in the OLS estimation of the ATT, or in the estimation of the propensity-scores. These four specifications are the same as those discussed in Table 3. Throughout Table 4, the outcome of interest is the KS4 test-score averaged across English, Mathematics and Science, and standardized to have mean zero and unitary standard deviation. In the first column of the table (not numbered), we reproduce the unconditional mean difference in the outcome between treated pupils and students in non-xl club schools. Column (1) presents ordinary least squares (OLS) estimates of the policy-effect. Next, Column (2) presents nearest-neighbour matching estimates of the ATT, while Column (3) presents matching results that use the five closest neighbours combined with a 0.0001 caliper. Both matching estimators are computed for the units on the common support and nearest neighbours are matched with replacement; standard errors are bootstrapped using 100 repetitions. $^{12}$

Comparison of the unconditional mean difference with OLS results in Column (1) shows that controlling for individual characteristics in a linear fashion greatly reduces the size of the negative estimated impact of the policy across all specifications. This effect shrinks by around a factor of eight, from -1.38 to -0.17 , in our richest specifications (Rows (2) and (4)).

\footnotetext{
${ }^{12}$ Note that we experimented with other matching algorithms, in particular with Local Linear Regression (LLR) matching with $2 \%$ trimming, and reached similar conclusions. Results are not tabulated, but available from the authors.
} 
Next, matching results are presented in Columns (2) and (3). Appendix Table 3 reports a battery of tests on the validity of the chosen matching algorithms. For all specifications, treated and control units do not significantly differ in terms of their observables after matching. Note also that at most three treated units are lost out of the common support areas when using the single nearest matching method, whereas no controls are dropped because of this restriction. This confirms the point made above that Figure 2 hides part of the empirical action.

The figures in Columns (2) and (3) of Table 4 reveal that the negative difference in the outcomes of treated and control students is further reduced when using a matching approach combined with Specification 2 and Specification 4. OLS estimates are in the order of negative 17 percent of a standard deviation, whereas matching estimates come down to around $-0.13 /-0.15$. Nevertheless, the opposite is true for Specification 3 (and to a much lesser extent for Specification 1), where we only match on KS2 test scores and individual characteristics: both propensity-score matching estimates are now more negative than OLS, at $-0.39 /-0.42$ versus -0.29 . An explanation for this pattern can be found in some facts noted above. First, xl clubs pupils have lower levels of achievement at both KS2 and KS3, relative to students in non-xl club schools, as well as negative and significantly lower KS2-to-KS3 value-added (see Table 2). Second, as revealed by the results in Table 3, KS3 test scores have a stronger effect on the chances of being enrolled in an xl club, than KS2 attainments. Taken together, these two aspects suggest that by matching pupils on the earliest Key Stage test scores only, we create 'bad' treated-controls matched units - or at least 'worse' pairs than if we matched on KS3 - and end up magnifying the differences between xl clubs students and matched pupils in KS4 outcomes.

All in all, the most important lesson learned so far is that using a matching approach to control for pupil observable characteristics in a more flexible way than with OLS does not change the overall message: if selection operated only through observables, the effect of the policy on pupil test scores at KS4 would be significantly negative. However, given the discussion in Section 2.2 about pupil selection for the programme, it is hard to believe that the CIA and similar assumptions advocated by cross- 
sectional estimators hold in our settings. Therefore, in the next section, we go on to explicitly exploit the longitudinal dimension of our dataset in order to control for the effects of unobervables.

\subsection{Accounting for unobservables: difference-in-differences and double-differences models}

In this section, we take advantage of the fact that we have access to pupils' test scores at various points in time to control for unobservable characteristics that might affect both enrolment in an $\mathrm{xl}$ club and students' achievement. To being with, we exploit test scores taken immediately before (KS3, age 14) and immediately after (age 16, KS4) the programme and compare KS3-to-KS4 value-added (KS4-KS3) for treated and control students. This approach is equivalent to a difference-in-differences set-up and allows us to partial-out the effects of time-fixed pupils' unobservables, such as ability, motivation and unobservable family background characteristics (see Meyer, 2005, and Heckman et al., 1997 and 1998 on the assumptions of difference-in-differences models). Our second set of estimates, instead, exploits test scores at three points in time, namely at age 11 (KS2) and age 14 (KS3), both before treated students were enrolled in an $\mathrm{xl} \mathrm{club,} \mathrm{and} \mathrm{at} \mathrm{age} 16(\mathrm{KS} 4)$, after the intervention took place. In this case, we compare the acceleration in value-added between ages 14 and 16 relative to the value-added between 11 and 14, that is $(\mathrm{KS} 4-\mathrm{KS} 3)-(\mathrm{KS} 3-\mathrm{KS} 2)$, for treated and control students. Empirical models with these features are often referred to as double-differences or random-growth models (see Heckman and Hotz, 1989; Michalopoulos et al., 2005), and allow to control for unosbervables that might affect enrolment in the programme and students' test score progression, such as increasing disengagement with school activities and flagging motivation. Put simply, these models help to control for linearly time-trending unobservable effects in students' outcomes. Note that, following the structure of the previous section, we estimate difference-in-differences and double-differences models using both OLS and a propensity-score matching approach. More details are provided in Appendix A.

Our results are presented in Table 5. The first column (not numbered) tabulates the unconditional mean difference in the outcome between treated pupils and students in non-xl club schools. Next, Column (1) presents ordinary least squares (OLS) estimates of the policy-effect, while Column (2) 
presents nearest-neighbour matching estimates, and Column (3) presents matching results that use the five closest neighbours, combined with a 0.0001 caliper.

Starting from the top, in Panel A we present results from the difference-in-differences models. In the first row we analyse the effects of the policy on the value-added between KS3 and KS4 (i.e. KS4-KS3). The unconditional mean difference in the outcome for xl-club and non xl-club students is -0.071 , and strongly significant. In the next three columns, we go on to estimate policy-effects that control for the variables used in Specification 1 of Table 3, using either least squares or propensity score methods. ${ }^{13}$ The OLS result in Column (1) shows that as soon as we add controls in a linear fashion, the policy-effect shrinks to -0.031 , and is no longer significantly different from zero. The matching estimates in Columns (2) and (3) provide a similar picture: pupils attending an xl club perform 1.5 to 2.7 percent of a standard deviation worse than matched controls, but this gap is not significantly different from zero.

As mentioned in Section 2.2, xl advisors and school teachers selected students for xl club activities on the basis of their assessment of pupils' progressive disengagement with education, future risk of exclusion and flagging motivation. These factors might have a negative effect on pupils' trends (valueadded) in test scores, rather than simply on overall levels of attainment. In this case, random-growth models that partial out the effects of linearly time-trending unobservables might be more appropriate.

To investigate this issue, in Row (2) of Table 5 we begin by presenting a similar analysis to Row (1) where the outcome of interest is now the value-added between KS2 and KS3. Both these tests were taken before some of the pupils enrolled in the programme, thus any effect of the policy on (KS3-KS2) would suggest that students with high/low value-added were more/less likely to attend an xl club. OLS results in Column (1) show a small negative, but not significant effect at -0.018 . Matching results in Columns (2) and (3) instead present more sizeable effects, at around -0.05 , and marginally significant. These

\footnotetext{
${ }^{13}$ Note that, when using single or double-differenced outcomes, we do not control for previous test-scores of pupils. Although some related studies (e.g. Heckman et al., 1998; Smith and Todd, 2005) have included lagged dependent variables in differenced models, in our case this strategy seems inappropriate. In fact, given the high persistence of test scores over time and the linearity in their effects, the inclusion of either KS2 or KS3 among the controls effectively nets the difference component out of our outcome variables, thus undermining the scope of the exercise.
} 
results are partly consistent with the evidence in Column (4) of Table 3, which showed that conditional on $\mathrm{KS} 3$, there is a small negative effect of KS2-to-KS3 value-added on the probability of joining a club. All in all, there is some weak evidence that students were selected for the programme on the basis of attributes associated with their trends in performance. Note also that it is unlikely that these findings pick-up an 'Ashenfelter's dip'-type dynamic (Ashenfelter, 1978): selection for the programme was not automatic and mechanically based on test scores being below a certain threshold, rather based on 'impressions' about students that teachers collected over three years of interaction.

In Panel B of Table 5 we present results from the double-differences models described above and detailed in Appendix A, where the dependent variable is the double difference in test scores (KS4-KS3)$(\mathrm{KS} 3-\mathrm{KS} 2) .{ }^{14}$ Some interesting results emerge. Both the unconditional mean difference and the OLS estimate of the policy effect are not statistically significant, and closer to zero than previously found, respectively at 0.008 and -0.013 . On the other hand, random-growth propensity-score matching models in Columns (2) and (3) produce some positive estimates, although these are not significant at the conventional levels. The policy-effect in Column (2), Row (3) is 0.025 , and further increases to 0.034 when matching on the five nearest neighbours (see Column (3)). A test on the difference between this last estimate and the OLS effect in Column (1) rejects the null of no difference with a p-value of 0.035.

These findings suggest that once we account for the effects of unobservable factors that affect trends in performance and control for observable characteristics in a highly flexible way using a matching approach, the policy had a beneficial impact on pupils' KS4 test scores (although not significant). However, this effect was worth at maximum 2.5 to 3.4 percent of a standard deviation, a small figure when compared to the achievement gap between xl club and regular students in terms of age-11 and age14 test scores, at about 1.2/1.3 standard deviations.

\footnotetext{
${ }^{14}$ When looking at the variable (KS4-KS3)-(KS3-KS2), we treat the time intervals between KS2 and KS3 and KS3 and KS4 as unitary 'education blocks', so that progress over the two periods can be compared by simply taking a double difference. Note that we analysed alternative models where we account for the fact that the two time-periods encompass a different number of years (2 vs. 3), and re-scaled the double difference to compute (KS4-KS3)-2/3×(KS3-KS2). We found qualitatively similar, although (mechanically) smaller effects of the programme. Results are available upon requests.
} 
In conclusion, it is also important to point out that these estimates might be upward biased by meanreversion. Indeed, one concern is that xl club pupils 'could not have got much worse' at KS4 since they started with very low grades at KS3. In other words, there might be a 'floor' effect such that the negative trend between KS3 and KS4 would have slowed down even in the absence of treatment. Moreover, as already discussed, there is only weak evidence that pupils were selected for the programme on the basis of characteristics correlated with their trends in performance. For these reasons, we believe results from difference-in-differences specifications are more reliable than those from double-differences models, and we consider the former specifications as our 'favourite'. To reiterate, these suggest that the xl club intervention was not effective at improving age-16 test scores of xl club students.

\subsection{Quantifying the role of selection on unobservables}

The results so far show that neglecting the role played by unobservables in determining pupils' selection for the $\mathrm{xl}$ club programme leads us to conclude that the policy had a negative effect on students' age 16 test scores. On the other hand, as soon as we move to models that allow us to partial out the effects of unobservables, we come to more positive conclusions: our central difference-in-differences estimates show that there is no significant gap in KS4 test scores between treated and matched pupils.

In order to shed more light on the role played by unobservables, we next adapt the approach of Altonji et al. (2005a) and (2005b) to investigate the following two empirical questions: (i) how much negative selection on unobservables do we need to drive the cross-sectional estimates of the policy-effect from negative and significant to zero; (ii) how sizeable our estimates would be if we imposed an equal amount of selection on observables and unobservables. These checks allow us to understand how much selection on unobservables relative to selection on observables we need in order to go from the negative cross-sectional OLS estimates of the policy-effect to the zero estimates obtained using the difference-indifferences models, and help us to shed some light on the credibility of the latter specifications. Note that the main difference between the Altonji et al. (2005b) original set-up and our empirical models is that 
our outcome is a continuous measure (test scores at KS4), rather than a binary variable. Appendix B provides details on how we have adapted the authors' method to our settings.

Results are reported in Table 6. The heading to the columns in the table refers to the constraint imposed on $\rho$, i.e. the correlation between the unobservables in the selection-equation and the treatmentequation in a Heckman-style model. Stated differently, $\rho$ captures the degree of (negative) sorting on unobservables into xl clubs. It is this parameter that we are interested in calibrating at different values in order to assess the robustness of our findings to varying degrees of selection on unobservables that are associated with lower levels of achievement and higher chances of enrolment in an xl club. Note that in the first column of the table we produce results where we impose $\rho=0$; in this case, we obtain the simple cross-sectional OLS results tabulated in Table 4. Note also that we perform our exercises using two alternative sets of controls, namely Specification 1 and Specification 2 discussed above.

Starting from Row 1, we find that the negative effect of the policy is significantly eroded as we progressively increase the amount of negative selection on unobservables. For $\rho=-0.35$, the effect is negative 0.060 , similar to the unconditional mean difference in value-added between xl club and regulars students (see Table 5), while for $\rho=-0.40$ the estimate becomes a positive 0.036 , although insignificant. Furthermore, if we impose an equal amount of selection on observables and unobservables $(\rho=-0.606)$, we find a significantly positive policy-effect at 0.417 .

Results reported in Row 2 are obtained using Specification 2 which further controls for KS3 test scores, and are even more compelling: with values of $\rho$ as small as -0.15 and -0.20 , estimates of the policy-effect turn insignificant negative and insignificant positive at -0.020 and 0.032 , respectively. These results are remarkably similar to the estimates reported in Table 5, where we used repeated test scores observations to directly control for pupil unobservables. Additionally, if we let the amount of selection on unobservables equate the amount of selection on osbervables $(\rho=-0.432)$, we find a positive and significant effect of the xl club intervention at 0.263 .

Taken together, these results provide some important pieces of evidence that support our previous analysis and conclusions. First, they show that students are more negatively sorted into the xl club 
programme if we do not control for pupils' prior test scores. This is consistent with the patterns of the estimates in Table 4. Second, we find that even conditional on students' prior attainments (KS3), a small absolute amount of selection on unosbervables (approximately $\rho=-0.17$ ) drives the policy-effect to zero. Given that the amount of negative selection on observables conditional on KS3 is approximately -0.43 (see the value of $\rho$ that identifies equal selection on observables and unobservables), this suggest that a shift in the distribution of unobservables of approximately 40 percent of the shift in the distribution of observables $(=17 / 43)$ shrinks the estimates of the policy-effect from negative and significant to zero. Stated differently, we do not need much sorting on unobservables relative to selection on observables in order to go from the cross-sectional OLS estimates of the policy-effect to the difference-in-differences results. This finding provides an indication of how important teachers' selection of xl club students based on aspects such as risk of school exclusion, persistent truanting and school disengagement should be in order to support estimates of the policy-effect based on difference-in-differences specifications. Finally, this set-up also allows us to pin down an upper bound for the effect of the xl club programme on pupils' test scores. Following the reasoning in Altonji et al. (2005a) and (2005b), we argue that given the richness of our specifications the amount of selection on observables identifies an upper bound to the amount of negative unobservable sorting. For reference, the adjusted R-squared of the model in Column (1), Row (2) of Table 4 is as sizeable as 0.748 . Therefore, it is very likely that models that impose an equal amount of negative observable and unobservable sorting identify an upper limit to the impact of the policy. Using our preferred specification (Specification 2), this upper bound would be 0.263 , or approximately 20 percent in the initial achievement gap between $\mathrm{xl}$ club and regular students.

\subsection{Further discussion}

Before moving ahead, an important remark regarding our econometric models is worth being made. The results discussed above showed that, if we analyse the impact of the policy on pupils' KS4 conditional on KS3, we find a negative and significant effect. On the other hand, if we use pupils' value-added to partial out the effect of unobservables, we estimate the policy-effect to be zero. 
This discrepancy is not particularly surprising in least squares models. Todd and Wolpin (2003) show that if test scores are a noisy proxy for pupil unobserved ability, the coefficient on the lagged test scores (KS3) will be downward biased. If selection into the programme is further (negatively) related to pupil unobserved ability, this bias will be transferred to the estimated impact of the policy, resulting in downward biased least square estimates of the policy-effect. On the other hand, if the restriction that the coefficient on lagged test scores (KS3) equals one can be assumed to hold, OLS estimation of differencein-differences models will result in unbiased estimates of the effect of the programme. ${ }^{15}$

However, the difference between value-added and lagged dependent variable models when using propensity-scores matching might be more unexpected. Indeed, Frolich (2008) argues that the issues highlighted here above do not contaminate policy-effects estimated using non-parametric matching models. His result holds under the assumption that the expected value of the individual unobservables within matched 'cells' is the same for treated and control units. Unfortunately, this condition is unlikely to hold in our setting because of two reasons. First, our propensity-score matching estimators control for pupil observable characteristics and lagged test scores in a semi-parametric way. Fully non-parametric ways of controlling for students' observables, in particular continuous measures of KS3 test scores, did not prove feasible. This is because we have too few treated students to meaningfully discretize KS3 test scores and match within cells defined by lagged test scores and other pupil characteristics. Second, even if fully non-parametric regression models were feasible, it is still unlikely that in our case treated and control pupils with the same observable characteristics and lagged test scores had, on average, the same unobservables. This is because of the very specific nature of the disadvantage and behavioural problems that characterise $\mathrm{xl}$ club pupils.

In conclusion, careful considerations of the underlying assumptions of our econometric models reinforces the intuition that cross-sectional OLS and matching models yield biased estimates of the policy-effect. On the other hand, models that more openly exploit the longitudinal dimension of the data

\footnotetext{
${ }^{15}$ Note that lacking a suitable instrument the assumption that the coefficient on lagged test scores is equal to one is not testable. For reference, in the OLS models of Column (1), Row (2) of Table 4 this coefficient was 0.794 (s.e. 0.003 ).
} 
and apply a difference-in-differences design give estimates that are closer to what the 'true' causal effect of the xl club intervention would be in the absence of sorting and selection.

\subsection{Robustness checks and heterogeneous policy-effects}

We conclude our analysis by discussing a series of robustness checks and some results about the heterogeneity of the policy-effects. Our focus is on the outcome (KS4-KS3), and estimates are obtained using a single nearest-neighbour matching approach. ${ }^{16}$ These are comparable with results in Row (1), Column (2) of Table 5.

To begin with, note that so far we have only considered KS4 average test scores across English, Mathematics and Science. This is because students have to sit exams in the three core subjects at ages 16, 14 and 11, which makes it easier to construct meaningful measures of educational progress over the Key Stages. However, on average, regular students sit for exams in ten different subjects at KS4. We thus rerun our analysis using outcomes at KS4 that are based on point scores averaged across all subjects taken, and standardized to take zero mean and unitary standard deviation. The results from this exercise show a smaller negative effect of the policy at -0.001 (with a standard error of 0.023 ) clearly not different from zero. This suggests that the programme impact might have been larger for possibly less academically demanding subjects, compared to the effect for English, Maths and Science. Given the nature of the xl club intervention and the type of pupils targeted, this seems a plausible result.

Next, we consider whether the intervention had an effect on non-treated pupils in xl club schools. These spill-over effects might emerge if, for example, $\mathrm{xl}$ club students become less disruptive as a result of the policy, thus positively contributing to the learning of other pupils during regular class-time (i.e. they became 'better' peers). Our findings show that the KS3-to-KS4 value-added of non-xl club students in xl club schools is approximately 0.018 above that of matched pupils in non-treated schools, and that this difference is significant. This result hints at the presence of some spill-over effects and is consistent

\footnotetext{
${ }^{16}$ All results from the sensitivity analysis, including also OLS and five nearest neighbours matching results, are not tabulated for space reasons, but are available from the authors upon request.
} 
with the evidence in Lavy et al. (2009), who show that a large fraction 'bad' peers in secondary schools (i.e. students from the bottom of the ability distribution) exerts a significantly negative effect on the learning of other school mates. Importantly, this finding also supports our claim that using non-treated students in treated schools to identify a 'comparison group' is not a suitable strategy.

We then go on to investigate the heterogeneity of our findings along a variety of dimensions. First, we stratify our sample by gender. Our estimates point to a positive effect of about 0.012 (s.e. 0.027 ) for boys, although this is not significantly different from zero. On the other hand, the impact of the policy is estimated to be precisely zero for girls at 0.000 (s.e. 0.031 ). A test for the equality of these two coefficients accepts the null with a p-value of 0.770 , thus strongly indicating that the policy effect was not significantly heterogeneous along the gender dimension. Similarly, we find no evidence of differences in the impact of the policy according to pupils' eligibility for FSM, with effects of -0.017 (s.e. 0.045) and-0.020 (s.e. 0.023) for FSM-eligible and non-FSM-eligible pupils, respectively. Finally, we compare our estimates for students in large schools with total enrolment above the median of the sample distribution (1146 students), to those for smaller schools with total roll below the median. The effect of the policy appears to be positive at 0.025 (s.e. 0.037 ) in smaller schools and negative at -0.023 (s.e. 0.029) in larger schools. However, both estimates are not significantly different from zero, and a test on the equality of these two coefficients accepts the null with a p-value of 0.307 .

To conclude, we also investigate whether our results are sensitive to non-random attrition in the sample. In particular, the longitudinal set-up of our analysis implies that we lose pupils whenever their KS2 or KS3 test scores are missing. In order to assess the robustness of our results the inclusion of these observations, we code missing KS2 and KS3 test scores to zeros, and include dummies for missing observations in all our specifications. Both the cross-sectional and the difference-in-differences/doubledifferences estimates of the policy-effect for this extended sample are similar to our previous findings. This is reassuring about the general validity of the results presented above. ${ }^{17}$

\footnotetext{
${ }^{17}$ Another concern with our analysis regards the validity of our data on participation in an xl club. As discussed in Section 3.1, we used several fully-detailed individual characteristics in order to link pupil administrative records and information
} 


\section{Concluding discussion}

In this paper, we have evaluated the effect of a remedial education intervention, called the $\mathrm{xl}$ club programme, that focussed on pupils aged 14 in English secondary schools. The intervention operated on a two-year programme, between ages 14 and 16, with approximately 13 students per club who met for at least 3 hours per week guided by an xl club advisor. The most remarkable feature of the programme was its focus on enhancing students' non-cognitive skills - such as confidence, self-esteem, motivation and locus-of-control - as a way to improve school attendance and raise young pupils' end-of-compulsoryeducation cognitive outcomes, that is test scores in standardized national exams at age 16.

Our findings on the effect of the policy on age 16 test scores vary depending on the way we control for pupil unobservable characteristics which might have simultaneously affected their chances of being enrolled in an xl club and their achievements. Our central estimates show that the policy did not have any positive (nor negative) impact on the test scores of treated pupils. A more generous reading of our findings is that the policy improved students' age 16 test scores by 2.5 to 3.4 percent of one standard deviation. Since xl club students started off with an achievement gap worth about 1.2/1.3 of one standard deviation in the age 11 and age 14 test scores relative to regular secondary school students, a cautious interpretation of our findings is that the policy was not effective at substantially narrowing xl club pupils' educational disadvantage. As such, our results cast some doubts on the broad effectiveness of policies that target students' non-cognitive skills as a means to improve their cognitive outcomes.

What could account for this lack of results? Several explanations could be advanced. First of all, the xl club activities might have simply not affected pupils' non-cognitive skills, which in turn would explain the lack of results on pupils' cognitive outcomes. This might occur, for example, if adolescent students' non-cognitive skills are not very malleable and crystallised at much earlier stages of their life. This explanation seems to contradict previous results in the literature (e.g. Knusden et al., 2006; Cunha and Heckman, 2008; and Carneiro and Heckman, 2003) that indicate that the most productive periods for

about enrolment in an xl club. This procedure might have introduced some noise, which could have in turn have affected our estimates. In order to assess this issue, we re-ran our analysis on the subset of xl clubs where at least 2/3 of the participants could be linked (including 95 percent of the 2233 treated pupils). Our results were fully confirmed. 
investment in non-cognitive skills concentrate during secondary schooling and adolescent years, and that non-cognitive skills are more amenable than cognitive abilities to being affected by interventions at later stages in one person's life. More importantly, this explanation also seems to contradict qualitative evidence collected by Browne and Evans (2007) on the effectiveness of the xl clubs in improving pupils' non-cognitive skills. For example, the authors report that treated students experienced (self-reported) improvements in motivation and attitudes towards education; positive effects on their behaviour towards other students and teachers; more maturity in dealing with problems and difficulties emerging during the learning time; increased self-esteem and confidence about their future educational achievements and labour market prospects. Similar perceptions were reported by the xl club advisors, as well as by teachers and head-teachers at the targeted schools.

A second possible explanation is that improvements in non-cognitive skills and pupils' motivation and awareness of the benefits of education did not translate into more time spent studying and learning at school, and less truanting (absences). However, once again, the qualitative evidence reported in Browne and Evans (2007) suggests that the policy improved pupils' patterns of attendance. Additionally, in some parallel research (Holmlund and Silva, 2008; results available upon request), we have tried to evaluate the impact of the xl club programme on pupils' absence rates. Unfortunately, repeated information about students' attendance patterns before and after the programme is not available, which makes it difficult to properly account for students' unobservables. Nevertheless, simulations based on the Altonji et al. (2005b) method discussed above and in Appendix B show that with very moderate degrees of selection on unobservables ( $\rho$ between 0.007 and 0.012 ) relative to degree of sorting on observables $(\rho$ approximately equals to 0.12 ) the policy had a positive and significant impact on pupils' attendance records. This was worth about a 15 percent reduction in authorised absences - usually justified with a parental note to the school and capturing less serious degrees of truanting behaviour - and a large 50 percent drop in un-authorised absences - more commonly associated with serious behavioural problems.

One last possible explanation is that, even if the policy had an effect on non-cognitive skills and attendance, this did not help pupils to significantly improve their cognitive outcomes, i.e. test scores in 
exams at age 16. This result is not necessarily inconsistent with previous findings in the literature. Although Heckman et al. (2006) and Cunha and Heckman (2008) show that that young students' noncognitive skills significantly affect their school achievements, the evidence discussed in Heckman (2000) suggests that programmes similar to the $\mathrm{xl}$ club initiative that solely focussed on improving adolescent students' motivation and awareness of education (such as the 'Big Brother/Big Sister' programme) did not significantly improved students' test score performance. More importantly, Cunha et al. (2006) suggest that the process of skill accumulation over an individual's life cycle is characterised by selfproductivity - skills acquired in early periods persist in the future - and complementarities - early skill investments enhance the productivity of human capital investment at later stages. The authors further argue that these dynamic complementarities help accounting for a large body of evidence that shows that later remedial interventions are not effective at addressing students' early and deeply rooted cognitive deficits. Given the background characteristics and history of poor achievements at early educational stages (age 11) of xl club pupils, a similar explanation might provide a rationale for our findings. Unfortunately, given the data at hand, these potential explanations must remain conjectures and are left open to future research. 


\section{References}

Abadie, A. (2005): "Semiparametric Difference-in-Differences Estimators”, Review of Economic Studies, vol. 72(1), pp. 1-19.

Altonji, J., T. Elder and C. Taber (2005a): "An Evaluation of the Instrumental Variable Strategies for Estimating the Effects of Catholic Schooling", Journal of Human Resources, vol. 40 (4), pp. 791-821.

Altonji, J., T. Elder and C. Taber (2005b): "Selection on Observed and Unobserved Variables: Assessing the Effectiveness of Catholic Schools", Journal of Political Economy, vol. 113(1), pp. 151-184.

Ashenfelter, O. (1978): "Estimating the Effects of Training Programs on Earning", The Review of Economics and Statistics, vol. 60(1), pp. 47-57.

Banerjee, A., S. Cole, E. Duflo and L. Linden (2007): "Remedying Education: Evidence from Two Randomized Experiments in India", Quarterly Journal of Economics, vol. 122(3), pp. 1235-1264.

Browne, A. and K. Evans (2007): "National Evaluation of The Prince's Trust xl Programme - Qualitative Evaluation", QA Research.

Caliendo, M and S. Kopeinig (2008): "Some Practical Guidance for the Implementation of Propensity Score Matching”, Journal of Economic Surveys, vol. 22(1), pp. 31-72.

Carneiro, P., C. Crawford and A. Goodman (2007): “The Impact of Early Cognitive and Non-Cognitive Skills on Later Outcomes", CEE Discussion Paper 00092.

Carneiro, P and J. Heckman (2003): "Human Capital Policy", in J. Heckman and A. Krueger (eds.), Inequality in America: What Role for Human Capital Policies?, Cambridge, Mass: MIT Press.

Cunha, F. and J. Heckman (2008): "Formulating, Identifying and Estimating the Technology of Cognitive and Noncognitive Skill Formation", Journal of Human Resources, vol. 43(4), pp. 738-782.

Cunha, F., J. Heckman, L. Lochner and D. Masterov (2006): "Interpreting the Evidence on Life Cycle Skill Formation", in E. Hanushek and F. Welch (eds.), Handbook of Economics of Education, Vol. 1, Chapter 12, North Holland-Elsevier, pp. 698-805.

Dehejia, R. (2005): "Practical Propensity Score Matching: A Reply to Smith and Todd", Journal of Econometrics, vol. 125, pp. 354-364.

Dehejia, R. and S. Wahba (1999): "Causal Effects in Nonexperimental Studies: Reevaluating the Evaluation of Training Programs", Journal of the American Statistical Association, vol. 94, pp. 1053-1062.

Dehejia, R. and S. Wahba (2002): "Propensity Sore-Matching Methods for Nonexperimental Causal Studies", Review of Economics and Statistics, vol. 84(1), pp. 151-161.

Emmerson, C., C. Frayne, S. McNally, O. Silva (2006): “Aimhigher: Excellence Challenge: A Policy Evaluation Using the Labour Force Survey", mimeo CEP-LSE.

Frolich, M. (2008): "Parametric and Non-parametric Regressions in the Presence of Endogenous Control Variables", International Statistical Review, forthcoming.

Heckman, J. (2000): "Policies to Foster Human Capital", Research in Economics, vol. 54, pp. 3-56.

Heckman, J. and J. Hotz (1989): "Choosing Among Alternative Nonexperimental Methods for Estimating the Impact of Social Programs: The Case of Manpower Training", Journal of the American Statistical Association, vol. 84, pp. 862- 874 .

Heckman, J., H. Ichimura and P. Todd (1997): "Matching as an Econometric Evaluation Estimator: Evidence from Evaluating a Job Training Programme", Review of Economic Studies, vol. 64, pp. 605-654.

Heckman, J., H. Ichimura and P. Todd (1998): "Matching as an Econometric Evaluation Estimator", Review of Economic Studies, vol. 65, pp. 261-294.

Heckman, J. and Y. Rubinstein (2001): "The Importance of Noncognitive Skills: Lessons from the GED Testing Program", American Economic Review, vol. 91(2), 145-149.

Heckman, J., J. Stixrud and S. Urzua (2006): "The Effects of Cognitive and Noncognitive Abilities on Labour Market Outcomes and Social Behavior", Journal of Labor Economics, vol. 24(3), 411-480.

Holmlund, H and O. Silva (2008): "Targeting Pupils at Risk of Exclusion: An Evaluation of the xl Club Programme", report to The Prince's Trust, London. 
Imbens, G. (2004): "Non Parametric Estimation of Average Treatment Effects Under Exogeneity: A Review", Review of Economics and Statistics, vol. 86, pp. 4-30.

Knudesn, E., J. Heckman, J. Cameron and J. Shonkoff (2006): "Economic, Neurobiological and Behavioral Perspectives on Building America's Future Workforce", NBER WP 12298.

Jacob, B and L. Lefgren (2004): "Remedial Education and Student Achievement: A Regression-Discontinuity Analysis", Review of Economics and Statistics, vol. 86(1), pp. 226-244.

LaLonde, R. (1986): "Evaluating the Econometrics Evaluations of Training Programs with Experimental Data", American Economic Review, vol. 76, pp. 604-620.

Lavy, V. and A. Schlosser (2005): "Targeted Remedial Education for Underperforming Teenagers: Costs and Benefits", Journal of Labor Economics, vol. 23(4), pp. 839-874.

Lavy, V., O. Silva and F. Weinhardt (2009): "The Good, The Bad and The Average: Evidence on the Scale and Nature of Ability Peer Effects in Schools", mimeo, London School of Economics.

Machin, S., S. McNally, C. Meghir (2007): "Resource and standards in urban schools", IZA DP 2653.

McNally, S. (2007): "Education, Education, Education: The Evidence on School Standards, Parental Choice and Staying-on", Policy Analysis, Centre for Economic Performance, London School of Economics.

Meyer, B. (1995): "Natural and Quasi-Experiments in Economics", Journal of Business and Economic Statistics, vol. 13(2), pp. 151-161.

Michalopoulos, C., H. Bloom and C. Hill (2004): Can Propensity-Score Methods Match the Findings from a Random Assignment Evaluation of Mandatory Welfare-to-Work Programs?", Review of Economics and Statistics, vol. 86(1), pp. 156-179.

OECD (2005): "Education at Glance", Organization for Economic Cooperation and Development, OECD, Paris. OECD (2007): "Social Expenditure Database: SOCX", Organization for Economic Cooperation and Development, OECD, Paris.

Pema, E. and S. Mehay (2009): "The Effect of High School JROTC on Student Achievement, Educational Attainment, and Enlist", Southern Economic Journal, forthcoming.

Rosenbaum, P and D. Rubin (1983): "The Central Role of the Propensity Score in Observational Studied for Caual Effects”, Biometrika, vol. 70(1), pp. 41-55.

Rubin, D. (1973): "Matching to Remove Bias in Observational Studies", Biometrics, vol. 29, pp. 159-183.

Segal, C. (2008): “Classroom Behaviour”, Journal of Human Resources, vol. 43(4), pp. 783-814.

Segal, C. (2009): "Misbehaviour, Education and Labour Market Outcomes", mimeo, UPF.

Smith, J. and P. Todd (2005): "Does Matching Overcome LaLonde's Critique of Nonexperimental Estimators?" Journal of Econometrics, vol. 125, pp. 305-353.

ter Weel, B. (2008): "The Noncognitive Determinants of Labor Market and Behavioral Outcomes: Introduction to the Symposium", Journal of Human Resources, vol. 43(4), pp. 729-737.

Todd, P. and K. Wolpin (2003): "On the Specification and Estimation of Production Functions for Cognitive Achievement”, Economic Journal, vol. 113(485), pp. F3-F33.

The Prince's Trust (2006): “The xl Strategy 05/06: Questions and Answers", official documentation on the xl clubs project, The Prince's Trust, London. 


\section{Tables}

Table 1: Preliminary matching at the school level; descriptive statistics and logit regression

\begin{tabular}{|c|c|c|c|}
\hline & (1) & (2) & (3) \\
\hline Variable & $\begin{array}{c}\text { Mean (std.dev.), } \\
\text { xl club schools }\end{array}$ & $\begin{array}{l}\text { Mean (std.dev.), } \\
\text { non xl club schools }\end{array}$ & $\begin{array}{l}\text { Marginal Effect } \\
\text { (std.error) }\end{array}$ \\
\hline Share spec. educational needs, with statement & $\begin{array}{c}0.031 \\
(0.018)\end{array}$ & $\begin{array}{r}0.026 \\
(0.019)\end{array}$ & $\begin{array}{c}0.639 \\
(0.419)\end{array}$ \\
\hline Share eligible for free school meals & $\begin{array}{r}0.197 \\
(0.130)\end{array}$ & $\begin{array}{c}0.144 \\
(0.131)\end{array}$ & $\begin{array}{c}0.213 \\
(0.111)\end{array}$ \\
\hline Share White & $\begin{array}{c}0.871 \\
(0.208)\end{array}$ & $\begin{array}{r}0.865 \\
(0.223)\end{array}$ & $\begin{array}{c}0.169 \\
(0.190)\end{array}$ \\
\hline Share Black & $\begin{array}{r}0.035 \\
(0.087)\end{array}$ & $\begin{array}{c}0.033 \\
(0.083)\end{array}$ & $\begin{array}{c}0.247 \\
(0.276)\end{array}$ \\
\hline Share Asian & $\begin{array}{c}0.062 \\
(0.136)\end{array}$ & $\begin{array}{r}0.069 \\
(0.159)\end{array}$ & $\begin{array}{r}0.132 \\
(0.197)\end{array}$ \\
\hline Share achieving 5 GCSEs $A *-C$ & $\begin{array}{c}0.414 \\
(0.151)\end{array}$ & $\begin{array}{c}0.523 \\
(0.186)\end{array}$ & $\begin{array}{l}-0.314 \\
(0.064)\end{array}$ \\
\hline Share sessions absent (authorised and unauthorised) & $\begin{array}{r}0.095 \\
(0.022)\end{array}$ & $\begin{array}{c}0.083 \\
(0.022)\end{array}$ & $\begin{array}{c}0.463 \\
(0.443)\end{array}$ \\
\hline Total pupil numbers & $\begin{array}{c}1015.145 \\
(354.18)\end{array}$ & $\begin{array}{c}1037.54 \\
(348.48)\end{array}$ & $\begin{array}{c}0.001 \\
(0.000)\end{array}$ \\
\hline Pupil-teacher ratio & $\begin{array}{l}15.905 \\
(1.904)\end{array}$ & $\begin{array}{l}15.706 \\
(1.854)\end{array}$ & $\begin{array}{r}0.006 \\
(0.004)\end{array}$ \\
\hline Observations & 351 & 1780 & 2131 \\
\hline
\end{tabular}

Note: Mean and standard deviations (in round parenthesis) of listed variables in Columns 1 and 2. Marginal effects from logit regression in Column 3 (with standard error in round parenthesis). Dependent variable takes value 1 for schools starting an $\mathrm{xl}$ club in 2004 and takes value zero for all schools that do not have any xl club between 2001 and 2006. Schools with xl clubs starting before 2004 or in 2005 and 2006, but not in 2004 were excluded from the sample. Logit specification also includes Local Authority dummies. "Other" is excluded ethnic group from specification. 
Figure 1: Predicted probability of treatment and common support

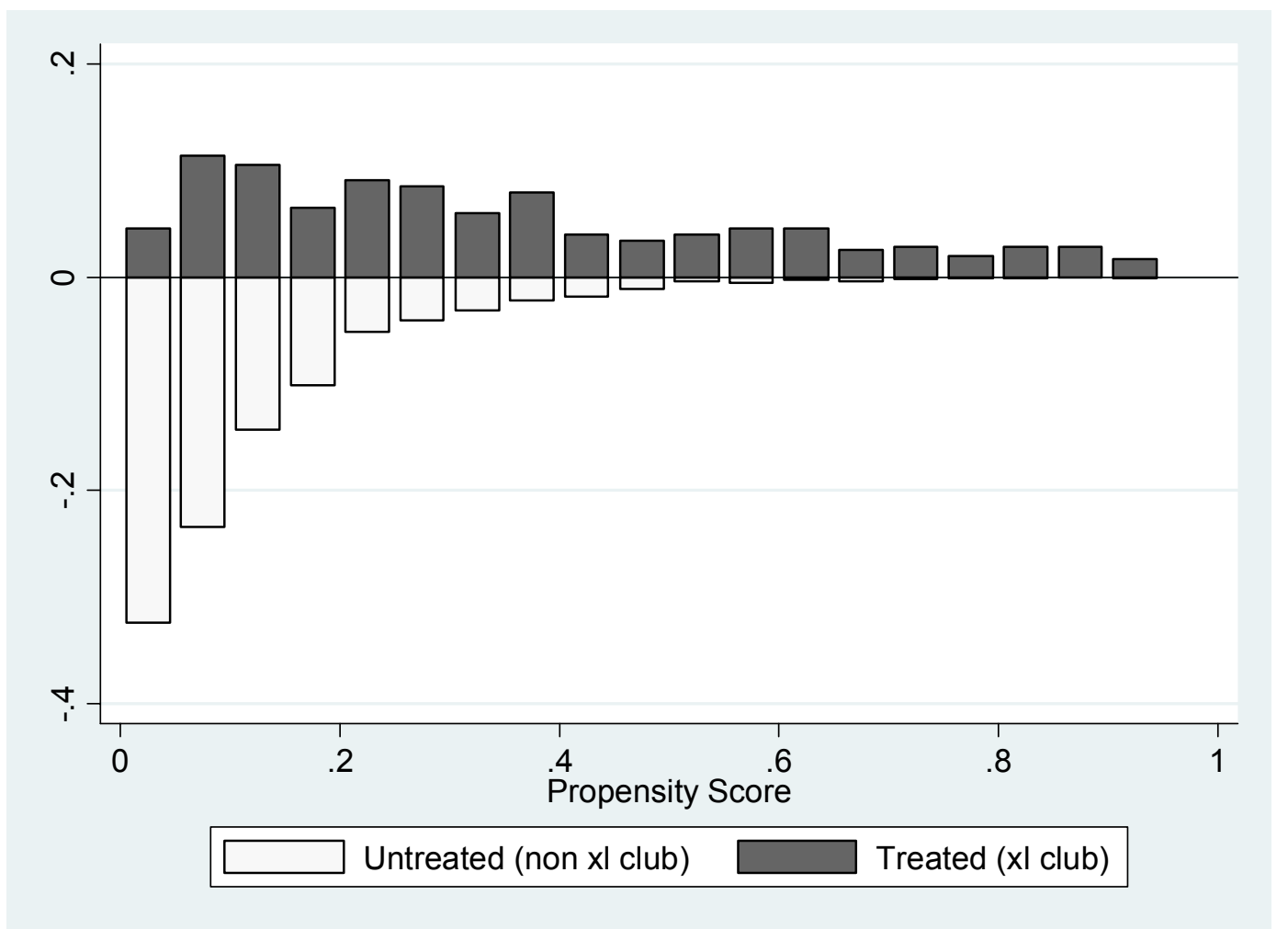

Note: The diagram plots histograms of the implied probability of treatment for xl club and non xl club schools. Probability estimates predicted using logit specification (see Table 1). School retained for the analysis are those falling within the common support; this spans the internal $[0.0097684,0.9199729]$ Total number of schools in the common support is 2033 (out of 2131), of which 350 (out of 351) are xl club members and 1683 (out of 1780) are non xl club schools. 
Table 2: Main variables, descriptive statistics for $\mathrm{xl}$ club and non $\mathrm{xl}$ club students

\begin{tabular}{|c|c|c|c|c|}
\hline & $(1)$ & (2) & (3) & (4) \\
\hline Variable & $\begin{array}{l}\text { xl club } \\
\text { students }\end{array}$ & $\begin{array}{l}\text { non xl club } \\
\text { students }\end{array}$ & $\begin{array}{l}\text { Difference } \\
\text { (1)-(2) }\end{array}$ & $\begin{array}{l}\text { T-stat. of } \\
\text { difference }\end{array}$ \\
\hline \multicolumn{5}{|l|}{ Panel A: Pupil achievement } \\
\hline KS4 average English, maths and science (EMS), standardized & $\begin{array}{l}-1.349 \\
(0.784)\end{array}$ & $\begin{array}{c}0.035 \\
(0.987)\end{array}$ & -1.384 & -66.062 \\
\hline KS3 average English, maths and science (EMS), standardized & $\begin{array}{l}-1.284 \\
(0.570)\end{array}$ & $\begin{array}{c}0.029 \\
(0.992)\end{array}$ & -1.313 & -62.411 \\
\hline KS2 average English, maths and science (EMS), standardized & $\begin{array}{l}-1.217 \\
(0.936)\end{array}$ & $\begin{array}{l}0.016 \\
(0.993)\end{array}$ & -1.233 & -58.494 \\
\hline (KS4 average EMS, standard.) - (KS3 average EMS, standard.) & $\begin{array}{l}-0.065 \\
(0.605)\end{array}$ & $\begin{array}{c}0.006 \\
(0.541)\end{array}$ & -0.071 & -6.186 \\
\hline (KS3 average EMS, standard.) - (KS2 average EMS, standard.) & $\begin{array}{l}-0.067 \\
(0.667)\end{array}$ & $\begin{array}{c}0.012 \\
(0.540)\end{array}$ & -0.079 & -6.886 \\
\hline$(\mathrm{KS} 4-\mathrm{KS} 3)-(\mathrm{KS} 3-\mathrm{KS} 2)$ & $\begin{array}{c}0.002 \\
(0.853)\end{array}$ & $\begin{array}{l}-0.006 \\
(0.791)\end{array}$ & 0.008 & 0.476 \\
\hline \multicolumn{5}{|l|}{ Panel B: Pupil characteristics } \\
\hline Male & $\begin{array}{r}0.616 \\
(0.486)\end{array}$ & $\begin{array}{c}0.496 \\
(0.500)\end{array}$ & 0.120 & 11.247 \\
\hline English as first language & $\begin{array}{r}0.945 \\
(0.227)\end{array}$ & $\begin{array}{c}0.923 \\
(0.266)\end{array}$ & 0.022 & 3.873 \\
\hline Eligible for free school meals & $\begin{array}{r}0.258 \\
(0.438)\end{array}$ & $\begin{array}{l}0.101 \\
(0.302)\end{array}$ & 0.157 & 24.384 \\
\hline Spec. educational needs status - action plan/plan plus & $\begin{array}{c}0.462 \\
(0.499)\end{array}$ & $\begin{array}{c}0.114 \\
(0.318)\end{array}$ & 0.348 & 51.263 \\
\hline Spec. educational needs with statement & $\begin{array}{r}0.057 \\
(0.232)\end{array}$ & $\begin{array}{c}0.010 \\
(0.102)\end{array}$ & 0.047 & 21.238 \\
\hline White & $\begin{array}{c}0.869 \\
(0.338)\end{array}$ & $\begin{array}{c}0.863 \\
(0.344)\end{array}$ & 0.006 & 0.838 \\
\hline Black & $\begin{array}{c}0.033 \\
(0.179)\end{array}$ & $\begin{array}{c}0.026 \\
(0.159)\end{array}$ & 0.007 & 2.129 \\
\hline Asian & $\begin{array}{r}0.037 \\
(0.188)\end{array}$ & $\begin{array}{c}0.060 \\
(0.237)\end{array}$ & -0.023 & -4.578 \\
\hline Chinese & $\begin{array}{r}0.000 \\
(0.021)\end{array}$ & $\begin{array}{c}0.002 \\
(0.050)\end{array}$ & -0.002 & -1.968 \\
\hline Other ethnic group & $\begin{array}{r}0.037 \\
(0.188)\end{array}$ & $\begin{array}{c}0.025 \\
(0.157)\end{array}$ & 0.012 & 3.385 \\
\hline Ethnicity unknown & $\begin{array}{c}0.024 \\
(0.154)\end{array}$ & $\begin{array}{c}0.024 \\
(0.152)\end{array}$ & 0.000 & 0.142 \\
\hline Observations & 2233 & 259189 & -- & -- \\
\hline
\end{tabular}

Note: Mean and standard deviations (in round parenthesis) of listed variables in Columns (1) and (2). Sample includes only pupils with non missing values of the listed variables and in xl club schools and non xl club schools belonging to the common support. Common support determined using implied probability of treatment at the school level. See Table 1 and Figure 1 for details. Standardized variables have zero mean and unitary variance. 
Table 3: Propensity score matching, marginal effects from various logit specifications

\begin{tabular}{|c|c|c|c|c|}
\hline & (1) & (2) & (3) & (4) \\
\hline Variable & Spec.1 & Spec. 2 & Spec.3 & Spec. 4 \\
\hline KS3 average EMS, standardized & -- & $\begin{array}{c}-0.0015 \\
(0.0001) \\
{[0.202]}\end{array}$ & -- & $\begin{array}{c}-0.0015 \\
(0.0001) \\
{[0.202]}\end{array}$ \\
\hline KS2 average EMS, standardized & -- & -- & $\begin{array}{c}-0.0014 \\
(0.0001) \\
{[0.441]}\end{array}$ & -- \\
\hline $\begin{array}{l}\text { (KS3 average EMS, standardized) - (KS2 average EMS, } \\
\text { standardized) }\end{array}$ & -- & -- & -- & $\begin{array}{l}-0.0001 \\
(0.0001) \\
{[0.959]}\end{array}$ \\
\hline Male & $\begin{array}{c}0.0007 \\
(0.0001) \\
{[1.357]}\end{array}$ & $\begin{array}{c}0.0003 \\
(0.0001) \\
{[1.386]}\end{array}$ & $\begin{array}{c}0.0007 \\
(0.0001) \\
{[1.522]}\end{array}$ & $\begin{array}{r}0.0003 \\
(0.0001) \\
{[1.378]}\end{array}$ \\
\hline English as first language & $\begin{array}{c}0.0006 \\
(0.0003) \\
{[1.366]}\end{array}$ & $\begin{array}{c}0.0003 \\
(0.0001) \\
{[1.499]}\end{array}$ & $\begin{array}{c}0.0007 \\
(0.0002) \\
{[1.712]}\end{array}$ & $\begin{array}{c}0.0003 \\
(0.0001) \\
{[1.488]}\end{array}$ \\
\hline Eligible for free school meals & $\begin{array}{c}0.0014 \\
(0.0002) \\
{[1.639]}\end{array}$ & $\begin{array}{c}0.0003 \\
(0.0001) \\
{[1.334]}\end{array}$ & $\begin{array}{c}0.0007 \\
(0.0001) \\
{[1.455]}\end{array}$ & $\begin{array}{r}0.0003 \\
(0.0001) \\
{[1.334]}\end{array}$ \\
\hline Spec. educational needs status - action plan/plan plus & $\begin{array}{c}0.0148 \\
(0.0018) \\
{[7.682]}\end{array}$ & $\begin{array}{c}0.0010 \\
(0.0002) \\
{[2.150]}\end{array}$ & $\begin{array}{c}0.0029 \\
(0.0005) \\
{[2.737]}\end{array}$ & $\begin{array}{c}0.0011 \\
(0.0002) \\
{[2.181]}\end{array}$ \\
\hline Spec. educational needs with statement & $\begin{array}{c}0.0082 \\
(0.0005) \\
{[5.383]}\end{array}$ & $\begin{array}{c}0.0008 \\
(0.0001) \\
{[1.921]}\end{array}$ & $\begin{array}{c}0.0024 \\
(0.0002) \\
{[2.579]}\end{array}$ & $\begin{array}{c}0.0008 \\
(0.0001) \\
{[1.934]}\end{array}$ \\
\hline Black & $\begin{array}{c}-0.0000 \\
(0.0003) \\
{[0.986]}\end{array}$ & $\begin{array}{c}-0.0002 \\
(0.0001) \\
{[0.822]}\end{array}$ & $\begin{array}{c}-0.0002 \\
(0.0002) \\
{[0.883]}\end{array}$ & $\begin{array}{c}-00002 \\
(0.0002) \\
{[0.822]}\end{array}$ \\
\hline Asian & $\begin{array}{c}-0.0003 \\
(0.0004) \\
{[0.858]}\end{array}$ & $\begin{array}{c}-0.0002 \\
(0.0001) \\
{[0.817]}\end{array}$ & $\begin{array}{c}-0.0003 \\
(0.0003) \\
{[0.822]}\end{array}$ & $\begin{array}{c}-0.0002 \\
(0.0001) \\
{[0.819]}\end{array}$ \\
\hline Chinese & $\begin{array}{c}-0.0018 \\
(0.0005) \\
{[0.202]}\end{array}$ & $\begin{array}{c}-0.0006 \\
(0.0003) \\
{[0.311]}\end{array}$ & $\begin{array}{c}-0.0013 \\
(0.0004) \\
{[0.245]}\end{array}$ & $\begin{array}{l}-0.0006 \\
(0.0003) \\
{[0.312]}\end{array}$ \\
\hline Other ethnic group & $\begin{array}{c}0.0005 \\
(0.0004) \\
{[1.219]}\end{array}$ & $\begin{array}{c}0.0002 \\
(0.0001) \\
{[1.253]}\end{array}$ & $\begin{array}{c}0.0004 \\
(0.0003) \\
{[1.263]}\end{array}$ & $\begin{array}{r}0.0002 \\
(0.0001) \\
{[1.252]}\end{array}$ \\
\hline Ethnicity unknown & $\begin{array}{l}-0.0009 \\
(0.0002) \\
{[0.592]}\end{array}$ & $\begin{array}{l}-0.0004 \\
(0.0001) \\
{[0.564]}\end{array}$ & $\begin{array}{c}-0.0007 \\
(0.0002) \\
{[0.599]}\end{array}$ & $\begin{array}{l}-0.0004 \\
(0.0001) \\
{[0.563]}\end{array}$ \\
\hline Pseudo R-Squared & 0.2573 & 0.3367 & 0.3012 & 0.3368 \\
\hline Percentage correctly predicted, $x$ l club pupils & 78.59 & 84.64 & 82.53 & 84.51 \\
\hline Percentage correctly predicted, non xl club pupils & 81.65 & 84.10 & 83.53 & 84.10 \\
\hline Additional school and census controls + LA dummies & Yes & Yes & Yes & Yes \\
\hline
\end{tabular}

Note: Dependent variable is dichotomous indicator taking value one if pupil belongs to an xl club and zero otherwise. Percentage of pupils treated in xl club is 0.85 percent. Number of observations 261,422 . Table presents marginal effects and standard errors (in parenthesis) from logit model. Odds ratios reported in square brackets. Specifications additionally include: School and census controls as listed in Appendix Table 2; and squared terms of "Share eligible for free school meals", "Share spec. educational needs with statement", "Share spec. educational needs without statement", "Share Black", "Share Asian", "Share Chinese", "Share other ethnicity", "Total pupil numbers", and "Pupil-teacher ratio"; and LA dummies. 
Figure 2: Predicted probability of treatment and common support

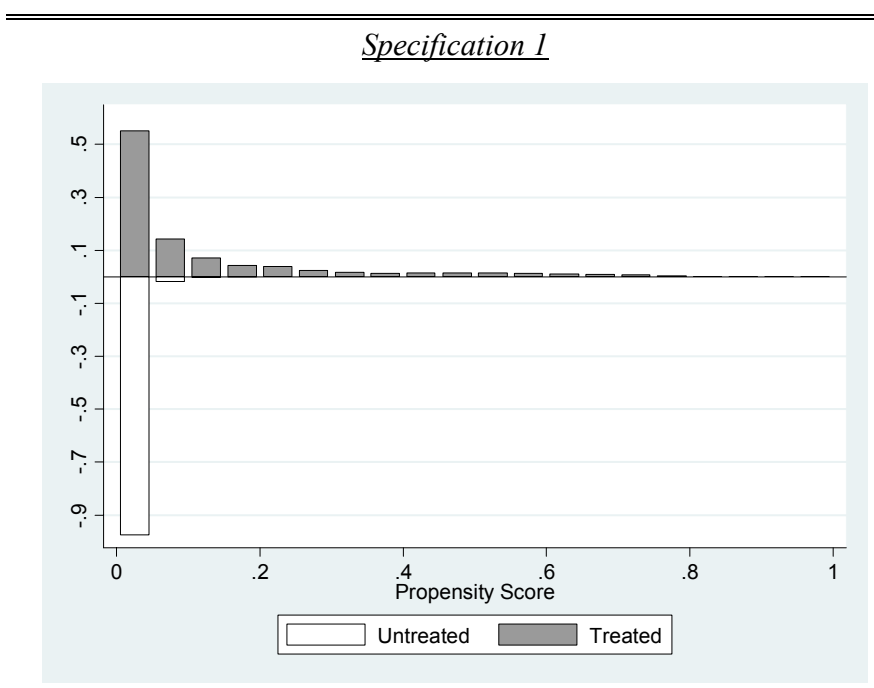

Specification 3
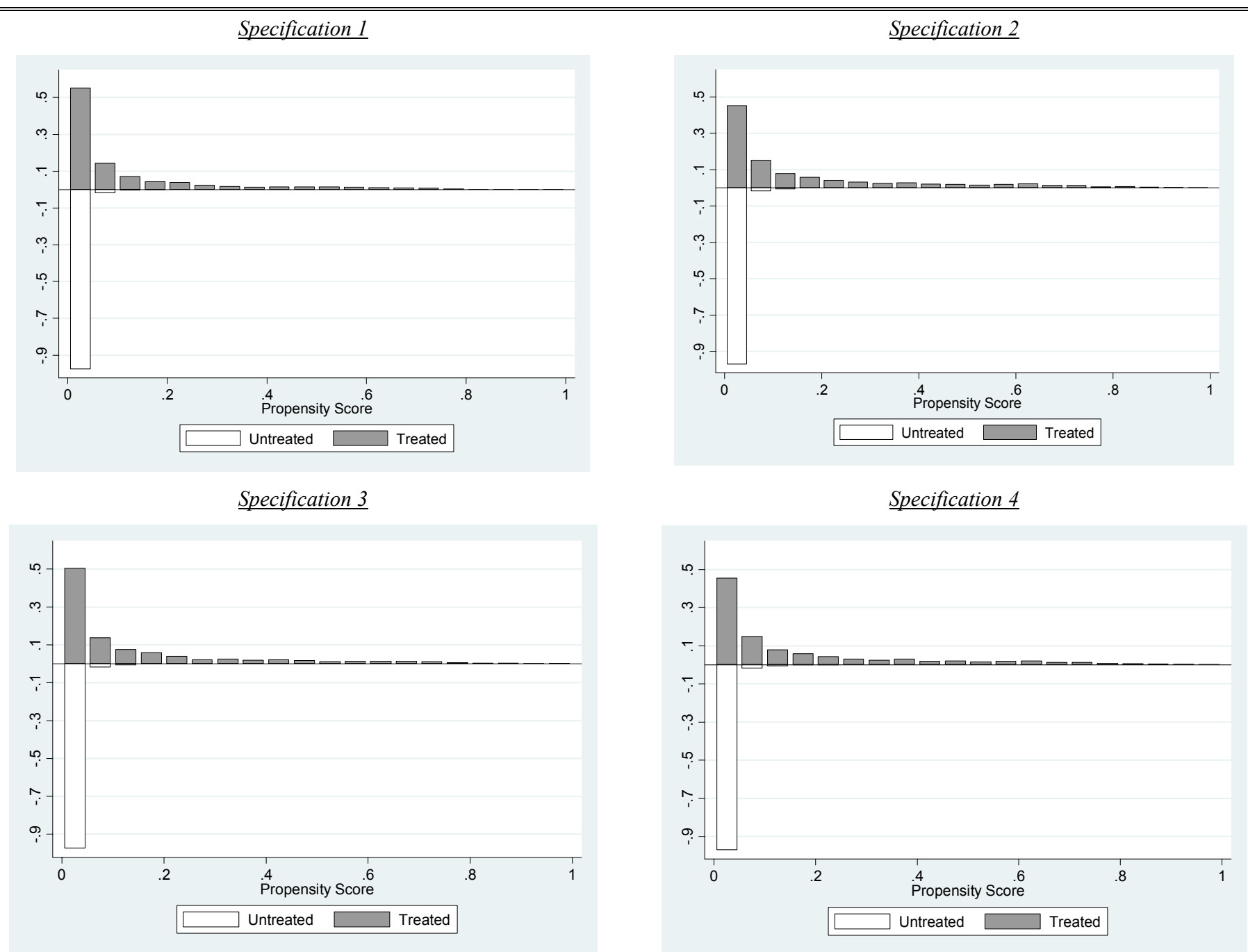

Note: Diagrams plot histograms of implied probability of treatment for xl club and non xl club pupils. Probability estimates predicted using logit specification. See Table 3 for various specifications. Percentage of pupils treated in xl club is 0.85 percent. Number of observations 261,422. 
Table 4: OLS and matching results, controlling for pupil observable characteristics

\begin{tabular}{|c|c|c|c|c|}
\hline & \multicolumn{4}{|c|}{ Dependent Variable: KS4 average EMS, standardized } \\
\hline & -- & (1) & $(2)$ & (3) \\
\hline $\begin{array}{l}\text { Effect of attending an xl club } \\
\text { for various specifications: }\end{array}$ & $\begin{array}{c}\text { Unconditional } \\
\text { difference }\end{array}$ & OLS & $\begin{array}{c}\text { Nearest } \\
\text { neighbour }\end{array}$ & $\begin{array}{c}5 \text { Nearest; } \\
\text { caliper }(0.0001)\end{array}$ \\
\hline $\begin{array}{l}\text { Specification 1: } \\
\text { no Key Stage controls }\end{array}$ & $\begin{array}{l}-1.384 \\
(0.021)\end{array}$ & $\begin{array}{l}-0.726 \\
(0.024)\end{array}$ & $\begin{array}{l}-0.745 \\
(0.036)\end{array}$ & $\begin{array}{l}-0.789 \\
(0.025)\end{array}$ \\
\hline $\begin{array}{l}\text { Specification 2: } \\
\text { controlling for KS3 only }\end{array}$ & -- & $\begin{array}{c}-0.174 \\
(0.0234)\end{array}$ & $\begin{array}{l}-0.134 \\
(0.025)\end{array}$ & $\begin{array}{l}-0.169 \\
(0.022)\end{array}$ \\
\hline $\begin{array}{l}\text { Specification } 3 \text { : } \\
\text { controlling for KS2 only }\end{array}$ & -- & $\begin{array}{l}-0.295 \\
(0.029)\end{array}$ & $\begin{array}{l}-0.386 \\
(0.032)\end{array}$ & $\begin{array}{l}-0.423 \\
(0.025)\end{array}$ \\
\hline $\begin{array}{l}\text { Specification 4: } \\
\text { controlling for } \mathrm{KS} 3 \text { and }(\mathrm{KS} 3-\mathrm{KS} 2)\end{array}$ & -- & $\begin{array}{l}-0.173 \\
(0.023)\end{array}$ & $\begin{array}{l}-0.151 \\
(0.023)\end{array}$ & $\begin{array}{l}-0.172 \\
(0.021)\end{array}$ \\
\hline
\end{tabular}

Note: Dependent variable in all columns is KS4 average in English, Maths and Science (EMS), standardized (zero mean and unitary variance). OLS specifications include controls as detailed in Table 3. Standard errors in Column (1) cluster at the LA level. Standard errors in Column (2) and (3) bootstrapped using 100 repetitions. Nearest neighbour and 5 nearest neighbours are with replacement and on the common support; 5 nearest neighbours further imposes a 0.0001 caliper (approx. 0.01 percent of the maximum p-score distance).

Table 5: OLS and matching results, accounting for pupil unobservables

\begin{tabular}{llcccc}
\hline \hline & -- & $(1)$ & $(2)$ & $(3)$ & \\
\hline $\begin{array}{l}\text { Effect of attending an } \mathrm{xl} \text { club for various } \\
\text { outcomes: }\end{array}$ & $\begin{array}{c}\text { Unconditional } \\
\text { difference }\end{array}$ & OLS & $\begin{array}{c}\text { Nearest } \\
\text { neighbour }\end{array}$ & $\begin{array}{c}5 \text { Nearest; } \\
\text { caliper }(0.0001)\end{array}$ \\
\hline
\end{tabular}

\section{Panel A: Difference-in-differences models}

\begin{tabular}{|c|c|c|c|c|}
\hline $\begin{array}{l}\text { (KS4 EMS) - (KS3 EMS); } \\
\text { no Key Stage controls (spec.1) }\end{array}$ & $\begin{array}{l}-0.071 \\
(0.011)\end{array}$ & $\begin{array}{l}-0.031 \\
(0.025)\end{array}$ & $\begin{array}{l}-0.027 \\
(0.023)\end{array}$ & $\begin{array}{l}-0.015 \\
(0.019)\end{array}$ \\
\hline $\begin{array}{l}\text { (KS3 EMS) - (KS2 EMS); } \\
\text { no Key Stage controls (spec.1) }\end{array}$ & $\begin{array}{l}-0.079 \\
(0.011)\end{array}$ & $\begin{array}{l}-0.018 \\
(0.026)\end{array}$ & $\begin{array}{l}-0.052 \\
(0.024)\end{array}$ & $\begin{array}{l}-0.049 \\
(0.020)\end{array}$ \\
\hline \multicolumn{5}{|l|}{ Panel B: Random growth models } \\
\hline $\begin{array}{l}(\mathrm{KS} 4-\mathrm{KS} 3)-(\mathrm{KS} 3-\mathrm{KS} 2) \\
\text { no Key Stage controls (spec.1) }\end{array}$ & $\begin{array}{r}0.008 \\
(0.017)\end{array}$ & $\begin{array}{l}-0.013 \\
(0.035)\end{array}$ & $\begin{array}{r}0.025 \\
(0.033)\end{array}$ & $\begin{array}{r}0.034 \\
(0.027)\end{array}$ \\
\hline
\end{tabular}

\footnotetext{
Note: Dependent variable in row one is (KS4 average EMS, standardized) - (KS3 average EMS, standardized); dependent variable in row two is (KS3 average EMS, standardized) - (KS2 average EMS, standardized); dependent variable in row three is the double difference between (KS4 average EMS, standardized) - (KS3 average EMS, standardized) and (KS3 average EMS, standardized) - (KS2 average EMS, standardized). See body text for more details Controls are as in Specification 1; see Table 3 for details. Standard errors in round parenthesis. Standard errors in Column (1): clustered at the LA level. Standard errors in Column (2) and (3): bootstrapped with 100 repetitions. Nearest neighbour and 5 nearest neighbours are with replacement and on the common support; 5 nearest neighbours further imposes a 0.0001 caliper (approx. 0.01 percent of the maximum p-score distance).
} 
Table 6: Sensitivity analysis with constrained correlation between selection and treatment equation

\begin{tabular}{|c|c|c|c|c|c|c|c|c|c|c|}
\hline Outcome and specification & $\rho=0.00$ & $\rho=-0.05$ & $\rho=-0.10$ & $\rho=-0.15$ & $\rho=-0.20$ & $\rho=-0.25$ & $\rho=-0.30$ & $\rho=-0.35$ & $\rho=-0.40$ & Equal selection \\
\hline $\begin{array}{l}\text { KS4, average EMS stand; } \\
\text { specification } 1\end{array}$ & $\begin{array}{c}-0.726 \\
(0.024)\end{array}$ & $\begin{array}{r}-0.631 \\
(0.024)\end{array}$ & $\begin{array}{c}-0.536 \\
(0.024)\end{array}$ & $\begin{array}{r}-0.441 \\
(0.024)\end{array}$ & $\begin{array}{r}-0.345 \\
(0.024)\end{array}$ & $\begin{array}{r}-0.250 \\
(0.024)\end{array}$ & $\begin{array}{c}-0.155 \\
(0.023)\end{array}$ & $\begin{array}{r}-0.060 \\
(0.023)\end{array}$ & $\begin{array}{r}0.036 \\
(0.023)\end{array}$ & $\begin{array}{c}0.417 \\
(0.022)\end{array}$ \\
\hline $\begin{array}{l}\text { KS4, average EMS stand.; } \\
\text { specification } 2\end{array}$ & $\begin{array}{l}-0.174 \\
(0.023)\end{array}$ & $\begin{array}{l}-0.122 \\
(0.023)\end{array}$ & $\begin{array}{l}-0.071 \\
(0.023)\end{array}$ & $\begin{array}{l}-0.020 \\
(0.023)\end{array}$ & $\begin{array}{r}0.032 \\
(0.023)\end{array}$ & $\begin{array}{r}0.083 \\
(0.023)\end{array}$ & $\begin{array}{r}0.135 \\
(0.023)\end{array}$ & $\begin{array}{r}0.186 \\
(0.022)\end{array}$ & $\begin{array}{r}0.238 \\
(0.022)\end{array}$ & $\begin{array}{c}0.263 \\
(0.022)\end{array}$ \\
\hline
\end{tabular}

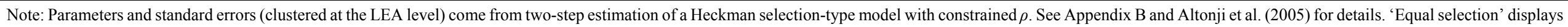
estimates where $\rho$ is constrained such that the amount of selection on observables equates the amount of selection on unobservables. Specifically, for row $1, \rho=-0.606$; and for row 2 , $\rho=-0.432$ give rise to 'equal selection'. 


\section{Appendix A: Empirical models and estimation methods}

\section{A1: Cross-sectional ordinary least squares and propensity-score matching models}

Cross-sectional estimates of the policy-effects are simply obtained by comparing KS4/age-16 test scores of xl club students (treated) to attainments of similar/matched pupils in schools where the programme was not being offered (controls).

Ordinary last squares (OLS) estimates of the effect of attending an xl club are obtained by fitting the following model:

$$
k s_{i 4}=\beta d_{i}+x_{i}^{\prime} \gamma+\eta k s_{i 3}+\mu k s_{i 2}+\xi_{i}
$$

Where $k s_{i 4}, k s_{3 i}$ and $k s_{2 i}$ are KS4/age 16, KS3/age 14 and KS2/age 11 test scores of pupil $i$, respectively; $x_{i}$ is a vector of pupil, school and neighbourhood characteristics; and $d_{i}$ is a dichotomous variable taking value one for pupils enrolled in an xl club, and value zero for pupils in schools where an $\mathrm{xl}$ club is not active. Note that in the empirical implementation, we build our specifications progressively. To begin with, we only control for the vector of characteristics $x_{i}^{\prime}$, and then go on to include either $k s_{i 3}$ or $k s_{i 2}$. Finally, in our last models, we include $k s_{i 3}$ and the value-added between KS2 and $\mathrm{KS} 3$, that is $\left(k s_{i 3}-k s_{i 2}\right)$. The parameter of interest is $\beta$, which captures the effect of the policy on treated pupils' test scores, that is the average treatment-on-the-treated (ATT).

Next, cross-sectional propensity-score matching estimates of the ATT are obtained as:

$$
A T T=\frac{1}{n} \sum_{i \in I_{1}}\left[k s_{1 i 4}-\sum_{j \in I_{0}} W(i, j) k s_{0 j 4}\right]
$$

In which $I_{l}$ is the set of xl club participants; $k s_{1 i 4}$ denotes KS4/age 16 test scores of treated pupils; $I_{0}$ represents the set of matched controls (i.e. comparable pupils in non-xl club schools), while $k s_{0 i 4}$ represents their KS4/age 16 test scores; $n$ is the number of matched treated individuals; and finally $W(i, j)$ is a weighting function that depends on the distance between the estimated propensity-scores $P_{i}$ for treated units and $P_{j}$ for matched controls. As already discussed in Section 4.2, we estimate pupils' 
propensity-scores parametrically using a logit model $\operatorname{Pr}\left(d_{i}=1 \mid Z\right)=\Lambda(Z \omega)$, where $d_{i}$ is a binary indicator taking value one if pupil $i$ is enrolled in an $\mathrm{xl}$ club and zero otherwise; $\Lambda($.$) is the logistic$ cumulative distribution function; $Z$ is a set of individual characteristics that vary depending on the exact specification of the empirical model; and finally $\omega$ is a vector of parameters. As for our OLS models, we build the specification of the propensity scores progressively. The exact details are provided in Table 3. Note also that we require that treated and control units fall in the common support area, and that we match using either the single nearest neighbour or the five nearest neighbours with a caliper restriction at 0.0001 (both with replacement). ${ }^{18}$

\section{A2: Difference-in-differences and double-differences models}

Difference-in-differences models exploit test scores taken immediately before (KS3/age-14) and immediately after (KS4/age-16) the programme and compare KS4-KS3 value-added for treated and similar control/matched students. On the other hand, double-differences models take advantage of information on test scores at three points in time, namely at ages 11 (KS2), 14 (KS3) and 16 (KS4) to compare the acceleration in value-added between ages 14 and 16 relative to the value-added between 11 and 14, that is (KS4-KS3)-(KS3-KS2), for treated and control students.

Ordinary last squares (OLS) estimates of the policy-effect from difference-in-differences and double-differences models are obtained by fitting the following two equations respectively:

$$
\begin{aligned}
& \left(k s_{i 4}-k s_{i 3}\right)=\beta d_{i}+x_{i}^{\prime} \gamma+\xi_{i} \\
& \left(k s_{i 4}-k s_{i 3}\right)-\left(k s_{i 3}-k s_{i 2}\right)=\beta d_{i}+x_{i}^{\prime} \gamma+\xi_{i}
\end{aligned}
$$

Where $k s_{i 4}, k s_{3 i}$ and $k s_{2 i}$ are once again KS4/age 16, KS3/age 14 and KS2/age 11 test scores of pupil $i$, respectively; $x_{i}$ is a vector of pupil, school and neighbourhood characteristics; and $d_{i}$ is a dichotomous variable taking value one for pupils enrolled in an xl club, and value zero for pupils in

\footnotetext{
${ }^{18}$ Note that in both cases the weighting function $W(i, j)$ is a 'step' function assigning positive weight(s) to the closest neighbour(s), and no weight to more distant ones. Note also that when using the five nearest neighbours, we assign an equal weight to each of them.
} 
schools where an $\mathrm{xl}$ club is not active. Note that when we use differenced outcomes, our specifications do not include lagged test scores on the right-hand side of equations A2.1 and A2.2. Once more, the parameter of interest is $\beta$, which captures the effect of the $\mathrm{xl}$ club programme on treated pupils' test scores, i.e. is the average treatment-on-the-treated (ATT).

Next, the matching analogues to the difference-in-differences and double-differences estimators of the ATT can be expressed as follows:

$$
\begin{aligned}
& \operatorname{ATT}_{\text {Diff-in-Diff }}=\frac{1}{n} \sum_{i \in I_{1} \cap S p}\left\{\left(k s_{1 i 4}-k s_{1 i 3}\right)-\sum_{j \in I_{0} \cap S p} W(i, j)\left(k s_{0 j 4}-k s_{0 j 3}\right)\right\} \\
& \operatorname{ATT}_{\text {Double-Diff }}=\frac{1}{n} \sum_{i \in I_{1} \cap S p}\left\{\left[\left(k s_{l i 4}-k s_{1 i 3}\right)-\left(k s_{l i 3}-k s_{l i 2}\right)\right]-\sum_{j \in I_{0} \cap S p} W(i, j)\left[\left(k s_{0 j 4}-k s_{0 j 3}\right)-\left(k s_{0 j 3}-k s_{0 j 2}\right)\right]\right\}
\end{aligned}
$$

Where $I_{l}$ is the set of xl club participants; $k s_{1 i 4}, k s_{1 i 3}$ and $k s_{1 i 2}$ denotes KS4/age 16, KS3/age 14 and KS2/age1 1 test scores of treated pupils, respectively; $I_{0}$ represents the set of matched controls, while $k s_{0 i 4}, k s_{0 i 3}$ and $k s_{0 i 2}$ denotes their KS4/age 16, KS3/age 14 and KS2/age11 test scores; $n$ is the number of matched treated individuals; and finally $W(i, j)$ is a weighting function that depends on the distance between the estimated propensity-scores $P_{i}$ for treated units and $P_{j}$ for matched controls (see footnote 18 for details). As discussed here above, we estimate pupils' propensity-scores parametrically using a logit model. As for the OLS models, the specification of the propensity scores does not include lagged measures of achievement when the outcomes of interest are test scores changes over time. Note finally that similarly to the cross-sectional propensity score matching estimators discussed above we require that treated and control units fall in the common support area, and we match using either the single nearest neighbour or the five nearest neighbours with a caliper restriction at 0.0001 (both with replacement). 


\section{Appendix B: Quantifying the role of selection on unobservables}

In this appendix section we describe our implementation of the Altonji et al. (2005b) methodology. In our case, the outcome of interest is a continuous indicator (test scores), rather than a binary variable, and we want to investigate: (a) how much negative selection on unobservables we need in order to drive our cross-sectional estimates of the policy effects from negative and significant to zero; and $(b)$ how robust these estimates are to the assumption of an equal amount of selection on observables and unobservables.

The foundation of this analysis is a Heckman-type selection model of the form:

$$
\begin{aligned}
& k s_{i 4}=\beta d_{i}+x_{i}^{\prime} \gamma+\eta k s_{i 3}+\xi_{i} \\
& d_{i}=I\left(x_{i}^{\prime} \lambda+\varphi k s_{i 3}+\vartheta_{i}>0\right)
\end{aligned}
$$

In which $k s_{i 4}$ and $k s_{3 i}$ are KS4/age 16 and KS3/age 14 test scores of pupil $i$; $x_{i}$ is a vector of pupil, school and neighbourhood characteristics; $d_{i}$ is a dichotomous variable taking value one for pupils enrolled in an xl club, and value zero for pupils in schools where an xl club is not active; $I($.$) is an$ indicator function taking values one if its argument is above zero; and finally the error terms $\xi_{i}$ and $\vartheta_{i}$ are jointly normally distributed with: $\mathrm{E}\left(\xi_{\mathrm{i}}\right)=0, \operatorname{Var}\left(\xi_{\mathrm{i}}\right)=\sigma^{2}, \mathrm{E}\left(\vartheta_{\mathrm{i}}\right)=0, \operatorname{Var}\left(\vartheta_{\mathrm{i}}\right)=1$ and $\operatorname{Corr}\left(\xi_{\mathrm{i}}, \vartheta_{i}\right)=\rho$. The parameter $\rho$ measures the correlation between unobservables in the xl club selection equation and in the test score equation. Stated differently, this factor captures the degree of selection on unobservables into $\mathrm{xl}$ clubs. It is this parameter that we are interested in calibrating at different values in order to assess the robustness of our findings to varying degrees of selection on unobservables.

As shown by Heckman (1979), the model in (B1) can be estimated by maximum likelihood or using a two-step method that first estimates the probability of being enrolled in an xl club $\left(d_{i}=1\right)$ parametrically using a probit model $\operatorname{Pr}\left(d_{i}=1 \mid x_{i}, k s_{i 3}\right)=\Phi\left(x_{i}^{\prime} \lambda+\varphi k s_{i 3}\right)$ and then estimates the following equation:

$$
\begin{aligned}
& k s_{i 4}=\beta d_{i}+x_{i j}^{\prime} \gamma+\eta k s_{i 3}+\theta^{*} \text { MillsRatio }_{i}+\xi_{i} \\
& \text { MillsRatio }_{i}=\frac{\phi\left(x_{i}^{\prime} \hat{\lambda}+\hat{\varphi} k s_{i 3}\right)}{\Phi\left(x_{i}^{\prime} \hat{\lambda}+\hat{\varphi} k s_{i 3}\right)}
\end{aligned}
$$


Where $\phi($.$) indicates the normal density distribution, \Phi($.$) represents the normal cumulative$ distribution, $\hat{\lambda}$ and $\hat{\varphi}$ are estimated using the probit first-stage, and $\theta=\sigma \rho$. Although the parameter $\rho$ is not non-parametrically identified without exclusion restrictions (i.e. a valid instrument), it can be constrained to predefined values in the estimation of system (3) by imposing a constraint on $\theta=\sigma \rho$ once an estimate for $\sigma$ is obtained (and maintained as $\rho$ changes) ${ }^{19}$. By setting $\rho$ to different values, we can explore the sensitivity of $\hat{\beta}$ to different assumptions about the degree of selection on unobservables into $\mathrm{xl}$ clubs and find the value of $\rho$ that is necessary to drive estimates of $\hat{\beta}$ from negative and significant values to zero. This allows us to answer question $(a)$ spelled out here above.

Additionally, Altonji et al. (2005b) discuss how to use this set-up to identify the value of $\rho$ which implies an equal amount of selection on observables and unobservables. They argue that, if a large number of observable characteristics are available for the investigation, the extent of selection on observables provides an upper bound for the amount selection on unobservables. To see how this applies to our case, consider the latent variable $d_{i}^{*}=\operatorname{Pr}\left(d_{i}=1 \mid x_{i}, k s_{i 3}\right)$ and assume we could run the following 'thought' regression:

$$
d_{i}^{*}=\delta_{0}+\delta_{1}\left[x_{i}^{\prime} \hat{\gamma}+\hat{\eta} k s_{i 3}\right]+\delta_{2} \xi_{i}
$$

In the Altonij et al. (2005b) sense, equal selection on observables and unobservables is obtained when $\delta_{1}=\delta_{2}$. Note now that in our case, where the outcome is a continuous variable and the term $\xi_{i}$ does not have unit variance, we have that:

$$
\begin{aligned}
& \delta_{1}=\frac{\operatorname{Cov}\left(\left(x_{i}^{\prime} \hat{\lambda}+\hat{\varphi} k s_{i 3}\right),\left(x_{i}^{\prime} \hat{\gamma}+\hat{\eta} k s_{i 3}\right)\right)}{\operatorname{Var}\left(x_{i}^{\prime} \hat{\gamma}+\hat{\eta} k s_{i 3}\right)} \\
& \delta_{2}=\frac{\operatorname{Cov}\left(\vartheta_{i}, \xi_{i}\right)}{\operatorname{Var}\left(\xi_{i}\right)}=\frac{\rho}{\sigma}
\end{aligned}
$$

\footnotetext{
${ }^{19}$ We obtain our estimate of $\sigma$ from unconstrained versions of system (3), where parametric identification is achieved using the non-linearities that characterize the Heckman-two step models.
} 
The constraint $\delta_{1}=\delta_{2}$ is therefore equivalent to the constraint $\rho / \sigma=\delta_{1}$ or $\sigma \rho=\sigma^{2} \delta_{1}$. Hence, in the estimation of (3), 'selection on observables equals selection on unobservables' implies the following constraint:

$$
\theta^{E S}=\sigma^{2} \frac{\operatorname{Cov}\left(\left(x_{i}^{\prime} \hat{\lambda}+\hat{\varphi} k s_{i 3}\right),\left(x_{i}^{\prime} \hat{\gamma}+\hat{\eta} k s_{i 3}\right)\right)}{\operatorname{Var}\left(x_{i}^{\prime} \hat{\gamma}+\hat{\varphi} k s_{i 3}\right)}
$$

Where the superscript $E S$ denotes 'equal selection'. Note that we do not estimate equation (3) with this constraint by full information maximum likelihood (as in Altonji et al., 2005b). Rather we use a twostep method as in Heckman (1979), and adopt a recursive grid-search numerical method to identify $\theta^{E S}$ that operates as follows: (i) estimate the two-step system described in equation (3) under different values of the constraint on $\theta=\sigma \rho$; (ii) after each of these estimations, calculate the value of $\hat{\rho}$ implied by the estimated coefficients from model (3), that is $\hat{\sigma} \frac{\operatorname{Cov}\left(\left(x_{i}^{\prime} \hat{\lambda}+\hat{\varphi} k s_{i 3}\right),\left(x_{i}^{\prime} \hat{\gamma}+\hat{\eta} k s_{i 3}\right)\right)}{\operatorname{Var}\left(x_{i}^{\prime} \hat{\gamma}+\hat{\varphi} k s_{i 3}\right)}$; (iii) plot the values $\hat{\rho}$ against the values of $\rho=\theta / \sigma$ (remember a constant $\sigma$ is estimated in a preliminary step, so changing values of $\theta$ can be mapped into changing values of $\rho$ ); (iv) identify the point at which the $(\hat{\rho}, \rho)$ plot crosses the 45 degree line: this is the point at which the amount of selection on observables is equal to amount of selection on unobservables; (iv) refine the search if the identified value of $\hat{\rho}$ and $\rho$ differ by more than a certain tolerance (say, fixed to 0.0005 ).

As discussed in Altonji et al. (2005b), the point at which negative selection on observables is as sizeable as negative selection on unobservables identifies an upper bound for the amount selection on unobservables that one should expect provided that a sufficient number of controls can be included in the empirical models. It follows that estimates of the impact of being enrolled in an xl club where we impose an equal amount of selection on observables and unobservables provide an upper bound to what the effect of taking part to $\mathrm{xl}$ club activities would be in the absence of sorting on unobservables. This helps answering our second question set out above in point (b). 


\section{Appendix Tables}

Appendix Table 1: Descriptive statistics; linked and non-linked xl club participants in secondary schools

\begin{tabular}{|c|c|c|c|}
\hline & $(1)$ & (2) & (3) \\
\hline Variable & $\begin{array}{c}\text { Linked, } \\
\text { work sample }\end{array}$ & $\begin{array}{l}\text { Linked, } \\
\text { with missing valued }\end{array}$ & $\begin{array}{l}\text { Non-linked, } \\
\text { in schools }\end{array}$ \\
\hline Male & $\begin{array}{r}0.620 \\
(0.485)\end{array}$ & $\begin{array}{c}0.671 \\
(0.470)\end{array}$ & $\begin{array}{r}0.642 \\
(0.480)\end{array}$ \\
\hline Age & $\begin{array}{l}14.038 \\
(0.390)\end{array}$ & $\begin{array}{l}14.025 \\
(0.297)\end{array}$ & $\begin{array}{l}14.241 \\
(0.556)\end{array}$ \\
\hline White & $\begin{array}{r}0.876 \\
(0.330)\end{array}$ & $\begin{array}{r}0.883 \\
(0.321)\end{array}$ & $\begin{array}{c}0.781 \\
(0.414)\end{array}$ \\
\hline Black & $\begin{array}{r}0.037 \\
(0.188)\end{array}$ & $\begin{array}{r}0.026 \\
(0.159)\end{array}$ & $\begin{array}{r}0.070 \\
(0.255)\end{array}$ \\
\hline Asian & $\begin{array}{r}0.037 \\
(0.188)\end{array}$ & $\begin{array}{r}0.037 \\
(0.190)\end{array}$ & $\begin{array}{r}0.065 \\
(0.246)\end{array}$ \\
\hline Other ethnic group & $\begin{array}{r}0.047 \\
(0.213)\end{array}$ & $\begin{array}{r}0.045 \\
(0.207)\end{array}$ & $\begin{array}{r}0.064 \\
(0.245)\end{array}$ \\
\hline Excluded from education & $\begin{array}{r}0.384 \\
(0.487)\end{array}$ & $\begin{array}{r}0.421 \\
(0.494)\end{array}$ & $\begin{array}{c}0.533 \\
(0.499)\end{array}$ \\
\hline Truant & $\begin{array}{r}0.275 \\
(0.447)\end{array}$ & $\begin{array}{r}0.334 \\
(0.472)\end{array}$ & $\begin{array}{c}0.398 \\
(0.490)\end{array}$ \\
\hline Disability & $\begin{array}{c}0.182 \\
(0.386)\end{array}$ & $\begin{array}{r}0.253 \\
(0.435)\end{array}$ & $\begin{array}{r}0.247 \\
(0.431)\end{array}$ \\
\hline Ex-offender & $\begin{array}{r}0.085 \\
(0.281)\end{array}$ & $\begin{array}{r}0.115 \\
(0.321)\end{array}$ & $\begin{array}{r}0.118 \\
(0.324)\end{array}$ \\
\hline Parent is lone-parent & $\begin{array}{r}0.030 \\
(0.172)\end{array}$ & $\begin{array}{r}0.038 \\
(0.191)\end{array}$ & $\begin{array}{r}0.043 \\
(0.203)\end{array}$ \\
\hline Pupil in care & $\begin{array}{r}0.030 \\
(0.170)\end{array}$ & $\begin{array}{r}0.043 \\
(0.203)\end{array}$ & $\begin{array}{r}0.078 \\
(0.269)\end{array}$ \\
\hline Asylum seeker & $\begin{array}{r}0.010 \\
(0.098)\end{array}$ & $\begin{array}{r}0.018 \\
(0.131)\end{array}$ & $\begin{array}{c}0.028 \\
(0.166)\end{array}$ \\
\hline Current Offender & $\begin{array}{r}0.059 \\
(0.236)\end{array}$ & $\begin{array}{r}0.075 \\
(0.264)\end{array}$ & $\begin{array}{r}0.087 \\
(0.282)\end{array}$ \\
\hline Observations & 2233 & 1895 & 1464 \\
\hline
\end{tabular}

Note: Mean and standard deviations (in round parenthesis) of listed variables. Data refers to the cohort of xl club students starting in September 2004 (aged 14). The total number of pupils in the xl club initiative in the 2004 cohort was 5898 . Total number of pupils in xl clubs in secondary schools: 5592 . For 306 pupils xl club was administered in youth clubs and/or in pupil referral units. These are non-educational institutions not recorded in administrative datasets. Information on the listed variables was collected by The Prince's Trust using a survey administered to xl club participants. Similar information was not collected for any control-group of pupils. 
Appendix Table 2: Additional controls, descriptive statistics for xl club and non xl club students

\begin{tabular}{|c|c|c|c|c|}
\hline \multirow{4}{*}{ Variable } & \multicolumn{2}{|c|}{ (1) } & \multicolumn{2}{|c|}{ (2) } \\
\hline & \multirow{2}{*}{\multicolumn{2}{|c|}{$\begin{array}{l}\text { xl club } \\
\text { students }\end{array}$}} & \multirow{2}{*}{\multicolumn{2}{|c|}{$\begin{array}{c}\text { non xl club } \\
\text { students }\end{array}$}} \\
\hline & & & & \\
\hline & $\underline{\text { Mean }}$ & Std. Dev. & $\underline{\text { Mean }}$ & Std. Dev. \\
\hline \multicolumn{5}{|l|}{ Panel A: School level characteristics } \\
\hline Share eligible for free school meals & 0.190 & $(0.121)$ & 0.131 & $(0.116)$ \\
\hline Share Spec. educational needs with statement & 0.029 & $(0.016)$ & 0.024 & $(0.015)$ \\
\hline Share Spec. educational needs without statement & 0.168 & $(0.080)$ & 0.130 & $(0.079)$ \\
\hline Share Black & 0.033 & $(0.083)$ & 0.028 & $(0.076)$ \\
\hline Share Asian & 0.061 & $(0.125)$ & 0.062 & $(0.151)$ \\
\hline Share Chinese & 0.004 & $(0.007)$ & 0.003 & $(0.005)$ \\
\hline Share other ethnicity & 0.029 & $(0.037)$ & 0.027 & $(0.033)$ \\
\hline Total pupil numbers & 1039.95 & $(344.25)$ & 1170.15 & $(355.12)$ \\
\hline Pupil-teacher ratio & 15.910 & $(2.193)$ & 15.924 & $(1.851)$ \\
\hline Pupil in Community School & 0.761 & $(0.426)$ & $(0.639)$ & $(0.480)$ \\
\hline Pupil in Voluntary Aided School & 0.103 & $(0.305)$ & $(0.144)$ & $(0.351)$ \\
\hline Pupil in Voluntary Controlled School & 0.021 & $(0.144)$ & $(0.034)$ & $(0.181)$ \\
\hline Pupil in Foundation School & 0.114 & $(0.318)$ & $(0.183)$ & $(0.387)$ \\
\hline \multicolumn{5}{|l|}{ Panel B: Census (OA) level characteristics } \\
\hline Share Christian & 0.709 & $(0.131)$ & 0.723 & $(0.145)$ \\
\hline Share other religion & 0.050 & $(0.108)$ & 0.057 & $(0.132)$ \\
\hline Share qual. level 2 & 0.183 & $(0.046)$ & 0.200 & $(0.048)$ \\
\hline Share qual. level 3 & 0.065 & $(0.039)$ & 0.074 & $(0.036)$ \\
\hline Share qual. level 4-5 & 0.129 & $(0.095)$ & 0.176 & $(0.106)$ \\
\hline Share other qual. & 0.070 & $(0.023)$ & 0.072 & $(0.025)$ \\
\hline Average household size & 2.465 & $(0.391)$ & 2.500 & $(0.396)$ \\
\hline Average household number of rooms & 5.134 & $(0.759)$ & 5.512 & $(0.923)$ \\
\hline Share of households with dependent children & 0.344 & $(0.111)$ & 0.336 & $(0.109)$ \\
\hline Share other ethnicity & 0.017 & $(0.024)$ & 0.015 & $(0.020)$ \\
\hline Share Asian & 0.038 & $(0.104)$ & 0.047 & $(0.128)$ \\
\hline Share Chinese & 0.007 & $(0.015)$ & 0.007 & $(0.014)$ \\
\hline Share Black & 0.024 & $(0.067)$ & 0.019 & $(0.055)$ \\
\hline Share active employee & 0.782 & $(0.087)$ & 0.787 & $(0.089)$ \\
\hline Share active self-employment & 0.098 & $(0.063)$ & 0.120 & $(0.067)$ \\
\hline Share active unemployment & 0.080 & $(0.061)$ & 0.052 & $(0.047)$ \\
\hline Share inactive student & 0.112 & $(0.081)$ & 0.119 & $(0.083)$ \\
\hline Share inactive retired & 0.354 & $(0.149)$ & 0.416 & $(0.162)$ \\
\hline Share inactive looking for job & 0.233 & $(0.092)$ & 0.221 & $(0.094)$ \\
\hline Share inactive sick & 0.196 & $(0.090)$ & 0.151 & $(0.085)$ \\
\hline Share in social housing & 0.323 & $(0.260)$ & 0.176 & $(0.221)$ \\
\hline Share in privately rented housing & 0.079 & $(0.087)$ & 0.076 & $(0.085)$ \\
\hline
\end{tabular}

Note: Mean and standard deviations (in round parenthesis) of listed variables in Columns (1) and (2). Sample includes only pupils with non missing values of the listed variables and in $\mathrm{xl}$ club schools and non $\mathrm{xl}$ club schools belonging to the common support. Common support determined using implied probability of treatment at the school level. See Table 1 and Figure 1 for details. There are $2233 \mathrm{xl}$ club pupils and 259,189 non xl club students. School level variables, omitted group: "Share of White". Census level variables, omitted groups: "Share no religion", "Share without qualifications", "Share of White"; "Share inactive looking after home"; "Share in owned housing". 
Appendix Table 3: Covariate balancing checks, before-after matching, single and five nearest neighbours methods

\begin{tabular}{|c|c|c|c|c|c|c|c|c|c|}
\hline & $\begin{array}{l}\text { N. of treated; } \\
\text { matched }\end{array}$ & $\begin{array}{l}\text { N. of treated; } \\
\text { off support }\end{array}$ & $\begin{array}{l}\text { N. of controls; } \\
\text { matched }\end{array}$ & $\begin{array}{l}\text { N. of controls; } \\
\text { off support }\end{array}$ & $\begin{array}{l}\text { Pseudo } \mathrm{R}^{2} \text {; } \\
\text { Before }\end{array}$ & $\begin{array}{c}\text { Pseudo } R^{2} ; \\
\text { after }\end{array}$ & $\begin{array}{l}\operatorname{Pr}>\chi^{2} \\
\text { after }\end{array}$ & $\begin{array}{c}\text { Median bias; } \\
\text { before }\end{array}$ & $\begin{array}{l}\begin{array}{c}\text { Median bias; } \\
\text { after }\end{array} \\
\text {. }\end{array}$ \\
\hline \multicolumn{10}{|l|}{ Panel A: Nearest neighbour } \\
\hline $\begin{array}{l}\text { Specification 1: } \\
\text { no Key Stage controls }\end{array}$ & 2231 & 2 & 1938 & 0 & 0.257 & 0.021 & 0.899 & 7.398 & 1.605 \\
\hline $\begin{array}{l}\text { Specification 2: } \\
\text { controlling for KS3 only }\end{array}$ & 2,230 & 3 & 1908 & 0 & 0.337 & 0.020 & 0.951 & 7.424 & 1.575 \\
\hline $\begin{array}{l}\text { Specification 3: } \\
\text { controlling for KS2 only }\end{array}$ & 2,233 & 0 & 1970 & 0 & 0.301 & 0.019 & 0.978 & 7.424 & 1.634 \\
\hline $\begin{array}{l}\text { Specification 4: } \\
\text { controlling for KS3 and (KS3 - KS2) }\end{array}$ & 2,230 & 3 & 1897 & 0 & 0.337 & 0.024 & 0.601 & 7.559 & 1.655 \\
\hline \multicolumn{10}{|c|}{ Panel B: 5 Nearest neighbours with caliper } \\
\hline $\begin{array}{l}\text { Specification 1: } \\
\text { no Key Stage controls }\end{array}$ & 1,901 & 332 & 1803 & 0 & 0.257 & 0.009 & 1.000 & 7.398 & 0.964 \\
\hline $\begin{array}{l}\text { Specification } 2 \text { : } \\
\text { controlling for KS3 only }\end{array}$ & 1,797 & 436 & 1729 & 0 & 0.337 & 0.011 & 1.000 & 7.424 & 1.196 \\
\hline $\begin{array}{l}\text { Specification 3: } \\
\text { controlling for KS2 only }\end{array}$ & 1,847 & 386 & 1783 & 0 & 0.301 & 0.008 & 1.000 & 7.424 & 0.926 \\
\hline $\begin{array}{l}\text { Specification 4: } \\
\text { controlling for KS3 and (KS3 - KS2) }\end{array}$ & 1,783 & 450 & 1718 & 0 & 0.337 & 0.010 & 1.000 & 7.559 & 0.946 \\
\hline
\end{tabular}

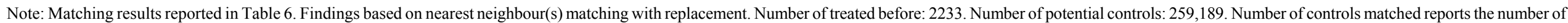

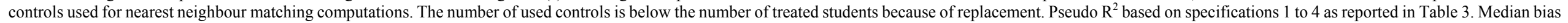
computed on all variables in the specification; full list of controls varies according to the specification. See Table 3 for details. 